\title{
Literature review of user needs, toward user requirements
}

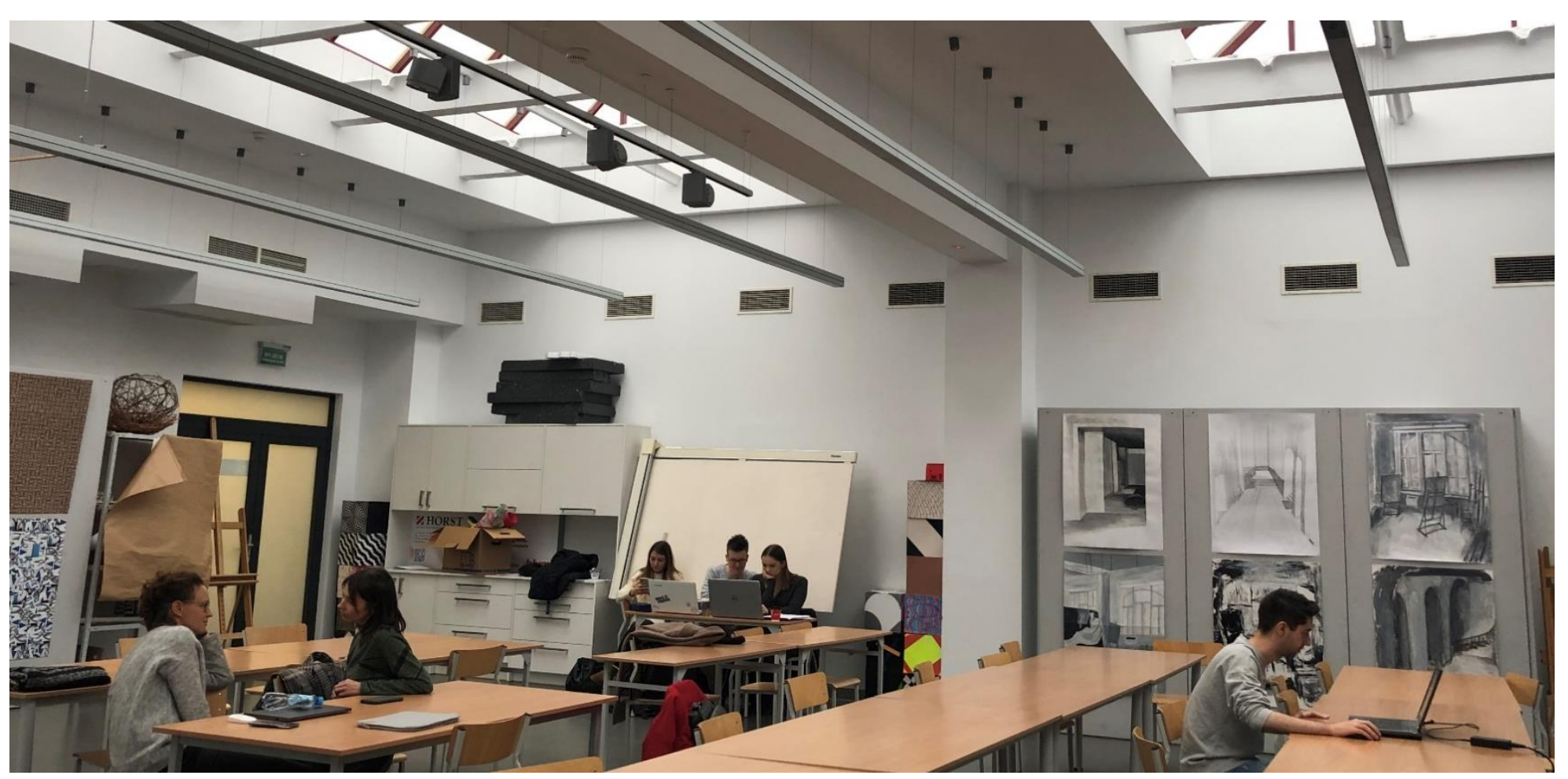

(C) Gdansk University of Technology

IEA SHC Task 61 / EBC Annex 77

Integrated Solutions for Daylighting and Electric Lighting

From component to user centered system efficiency 


\section{IEA Solar Heating and Cooling Technology Collaboration Programme (IEA SHC)}

The Solar Heating and Cooling Technology Collaboration Programme was founded in 1977 as one of the first multilateral technology initiatives ("Implementing Agreements") of the International Energy Agency. Its mission is "To enhance collective knowledge and application of solar heating and cooling through international collaboration to reach the goal set in the vision of solar thermal energy meeting $50 \%$ of low temperature heating and cooling demand by $2050 . "$

The members of the IEA SHC collaborate on projects (referred to as Tasks) in the field of research, development, demonstration (RD\&D), and test methods for solar thermal energy and solar buildings.

Research topics and the associated Tasks in parenthesis include:

- Solar Space Heating and Water Heating (Tasks 14, 19, 26, 44, 54)

- Solar Cooling (Tasks 25, 38, 48, 53, 65)

- Solar Heat for Industrial or Agricultural Processes (Tasks 29, 33, 49, 62, 64)

- Solar District Heating (Tasks 7, 45, 55)

- Solar Buildings/Architecture/Urban Planning (Tasks 8, 11, 12, 13, 20, 22, 23, 28, 37, 40, 41, 47, 51, 52, 56, 59, 63)

- Solar Thermal \& PV (Tasks 16, 35, 60)

- Daylighting/Lighting (Tasks 21, 31, 50,61)

- Materials/Components for Solar Heating and Cooling (Tasks 2, 3, 6, 10, 18, 27, 39)

- Standards, Certification, and Test Methods (Tasks 14, 24, 34, 43, 57)

- Resource Assessment (Tasks 1, 4, 5, 9, 17, 36, 46)

- Storage of Solar Heat (Tasks 7, 32, 42, 58)

In addition to our Task work, other activities of the IEA SHC include our:

> International Conference on Solar Heating and Cooling for Buildings and Industry

$>$ SHC Solar Academy

$>$ Solar Heat Worldwide annual statics report

$>$ Collaboration with solar thermal trade associations

\section{Country Members}

$\begin{array}{lll}\text { Australia } & \text { France } & \text { South Africa } \\ \text { Austria } & \text { Germany } & \text { Spain } \\ \text { Belgium } & \text { Italy } & \text { Sweden } \\ \text { Canada } & \text { Netherlands } & \text { Switzerland } \\ \text { China } & \text { Norway } & \text { Turkey } \\ \text { Denmark } & \text { Portugal } & \text { United Kingdom } \\ \text { European Commission } & \text { Slovakia } & \end{array}$

\section{Sponsor Members}

European Copper Institute

For more information on the IEA SHC work, including many free publications, please visit www. iea-shc. org. 


\section{Literature review of user needs, toward user requirements}

\section{Editor}

Barbara Szybinska Matusiak

\section{Authors}

Claudia Naves David Amorim, David Geisler-Moroder, Thorbjörn Laike, Justyna MartyniukPęczek, Barbara Szybinska Matusiak, Wilfried Pohl, Natalia Sokol

\section{0-27-09}

T61.A.1, DOI: 10.18777/ieashc-task61-2020-0001

The contents of this report do not necessarily reflect the viewpoints or policies of the International Energy Agency (IEA) or its member countries, the IEA Solar Heating and Cooling Technology Collaboration Programme (SHC TCP) members or the participating researchers. 


\section{Contents}



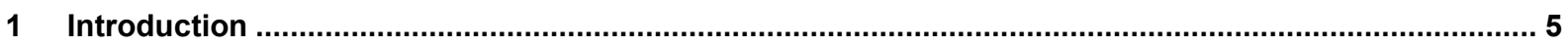

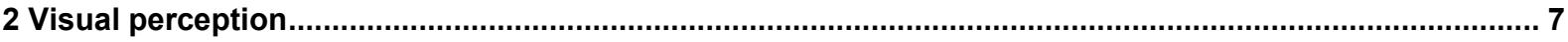

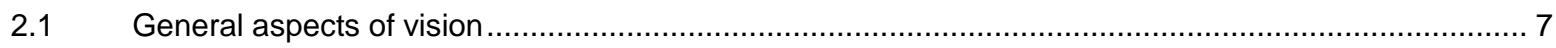

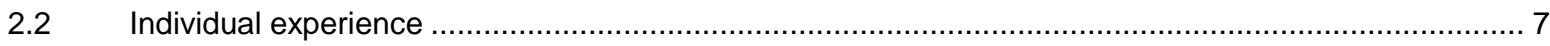

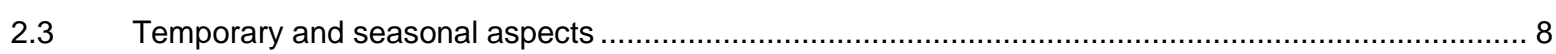

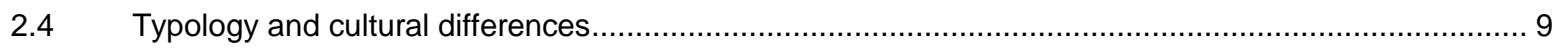

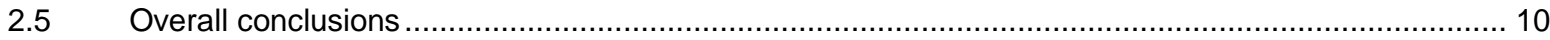



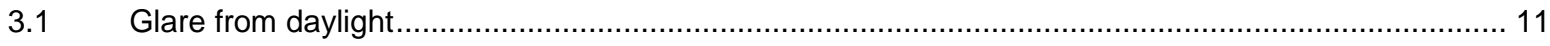

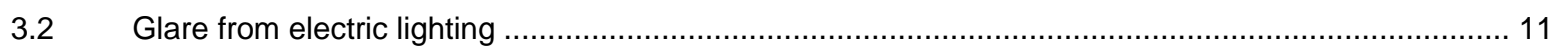

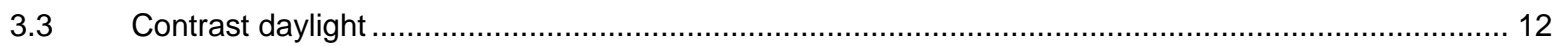

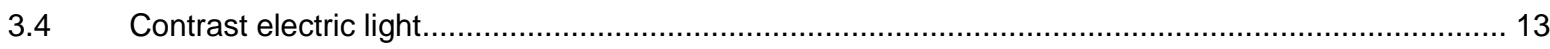

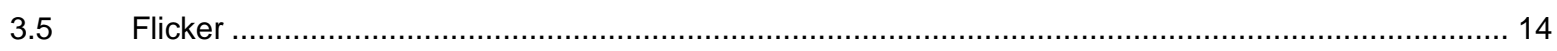



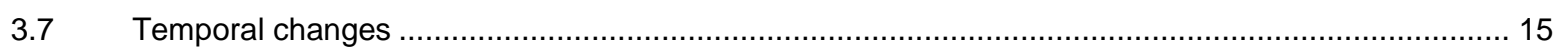



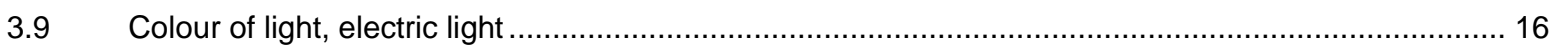

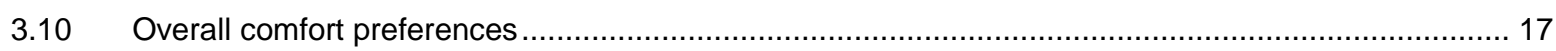



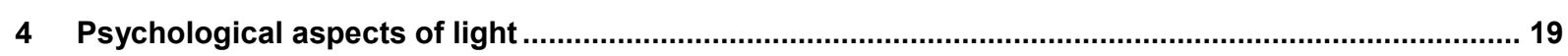

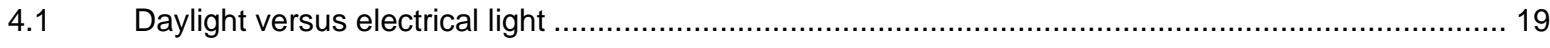

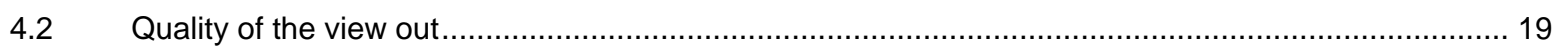

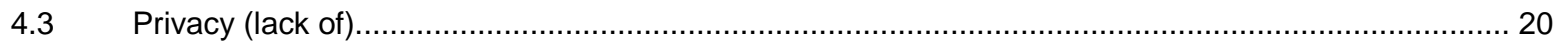



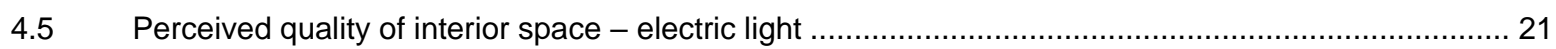

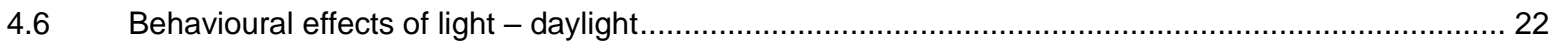

4.7 Behavioural effects of light - electric light and daylight ............................................................. 22

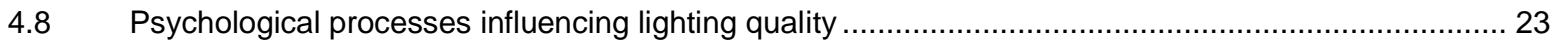

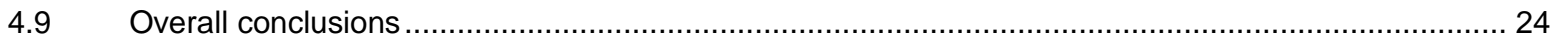

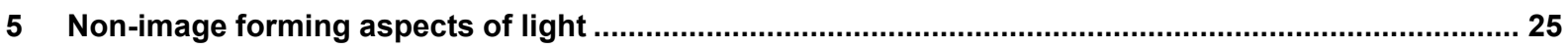

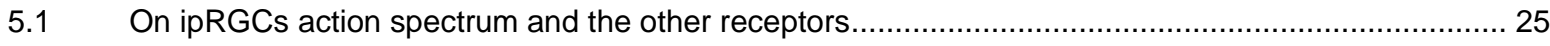

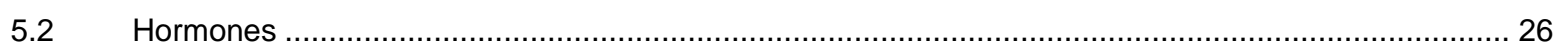

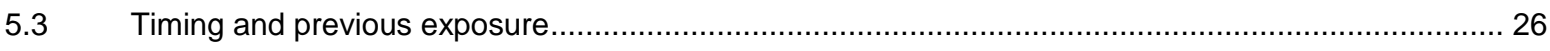

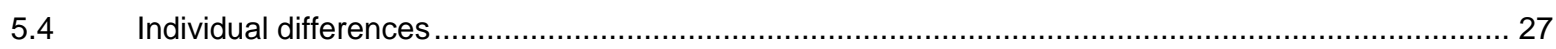

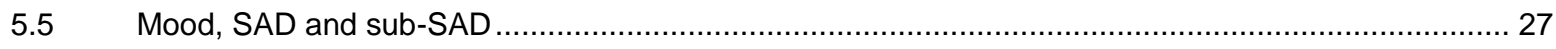

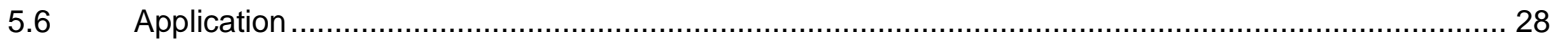

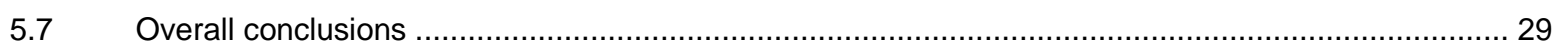

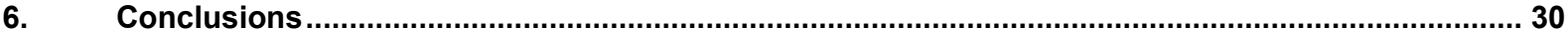




\section{Introduction}

This report has been developed in the frame of the IEA SHC Task 61 Subtask A "User requirements". The main objective was to rethink and reformulate user requirements to lighting (daylighting and electric lighting) in public buildings on the basis of a thorough literature study. The work is a joint effort of a number of scientists and represents collective knowledge in this topic.

The concept of Lighting quality is the one, among many lighting concepts, which expresses the user perspective best. Lighting quality is the important goal of lighting designers and planners; however, it is difficult to define and to measure. The following definition of lighting quality has been used for many years:

\section{Lighting quality is a concept that allows excellent vision while providing high comfort. (Kruisselbrink, Dangol and Rosemann) (2018)}

In this recent paper, the authors try to find measures that could be directly used for describing the lighting quality: quantity, glare, spectral power distribution, distribution of light, directionality and dynamics. The overview also shows that the luminance distribution is a suitable way for at least getting useful information of the lighting quality. If spectral distribution is added to these measurements an even better description of the lighting quality is obtained.

The above-mentioned definition of lighting quality focuses at humans, but it does not take into consideration aspects of light that have indirect and profound impact on human health and well-being. Those are the non-image forming aspects of light and some psychological aspects. In this report those additional aspects are included and structured in chapters as follows:

1. Perception of light

2. Visual Comfort

3. Psychological aspects of lighting (view out, perceived quality of space, privacy, etc.)

4. Non-image forming aspects of light (ipRGCs action spectrum, hormones, etc.)

By using these four different basic aspects we have the possibility to define several criteria for lighting quality, both image-forming and non-image forming. We have also the possibility to compare between qualities of electric lighting and daylighting. During the last twenty years the knowledge about light and lighting has developed and at the same time the technological development has been immense. Today we are able to get much more electrical lighting with less energy than ever before, but is the light of good quality? We need to develop evaluation methods that take all the qualitative aspect of illumination as well as the energy efficiency into account at the same time, to be able to evaluate the lighting conditions. Reliable and valid measures of light, as well as valid and reliable measures of user's reactions are needed as well.

\section{Photometric measures}

The photometric measures are derived from the basic SI-units for energy and have been adopted to the human vision. In photometry, luminous flux (or luminous power) is the measure of the perceived power of light. It differs from radiant flux (the measure of the total power of electromagnetic radiation) in that luminous flux accounts for the sensitivity of the eye by weighting the power at each wavelength with the luminosity function, which represents the eye's response to different wavelengths. The luminous flux is a weighted sum of the power at all wavelengths in the visible band. Light outside this band does not contribute. The luminous flux (in lumens, Im) is embedded in most lighting technical measures, e.g. illuminance $\left(\mathrm{Im} / \mathrm{m}^{2}\right)$ or luminous intensity $(\mathrm{Im} / \mathrm{sr})$. The ratio of the total luminous flux to the power applied to a light source is the luminous efficacy $(\mathrm{Im} / \mathrm{W})$ of a light source.

Measures of user's reactions

The photometric measures are not covering the non-image forming aspects in a good way. Here different measures are proposed, such as circadian stimulus (CS) or $\alpha$-opic equivalent daylight (D65) illuminance ( $\alpha$-opic EDI), but none of these are yet fully accepted worldwide. It is important to use measures for non-image impact of light to cover all aspects of lighting quality. 
In this report we have taken a broad view on the question of good lighting from all perspectives based on the current scientific knowledge within the field. Based on the literature study, updated user requirements considering both daylighting and electric lighting are proposed, see table 1 in the chapter 6 . Conclusions.

\section{Reference}

Thijs Kruisselbrink, Rajendra Dangol, Alexander Rosemann (2018) Photometric measurements of lighting quality: an overview. Building and Environment 138, 42-52 


\subsection{General aspects of vision}

Perception can be studied with the help of light fields that is characterized by a difference in its consistent structure between parts of a scene. In architectural lighting design, such a consistent structure in a part of a light field is called a light zone. Observers are able to distinguish the light conditions between the zones, which suggests an effect of light zones' orientation. Observers are also quite sensitive to the difference in the light flow of the light zones. In addition, participants showed idiosyncratic behaviour, especially for front-back-oriented light zones. In conclusion, findings show that observers are sensitive to differences in light field structure between two parts of a scene, which are called visual light zones.

A brief account of modern views of visual perception is given, related to the knowledge of lighting. There is evidence for thinking that some part of the phenomenon known as brightness constancy is the result of the structure of the nervous system. It is deduced that brightness constancy will hold most accurately where contrasts are low and are liable to break down when they are high.

Visual performance, understood as the speed and accuracy of processing visual information, is strongly influenced by lighting conditions. Daylight is a very good source of light to support visual performance during the daytime.

Recent research strongly suggests that the amount of light affects children as they grow and determines whether they will develop myopia or not. Myopia, or short-sightedness, is the most widespread visual disorder affecting young people, it has reached an epidemic level in Asia and is increasing everywhere. However, evidence that daylight in classrooms prevents myopia is lacking.

The risk of myopia is lowered by exposure to daylight and increased by activities performed at short visual distances (close-up work). A person with little exposure to daylight has a fivefold risk of developing myopia, which can rise as high as a 16 -fold risk if that person also performs close-up work.

\subsubsection{References}

Tatiana Kartashova, Huib de Ridder, Susan F. te Pas, Sylvia C. Pont. (2018) Visual light zones. i-Perception 9:3, 1-20 DOI: 10.1177/2041669518781381

Jay P.A. (1971) Lighting and visual perception, Lighting research and Technology 3:2, 133-146

Boyce, P. R. (2014) Human factors in lighting. CRC Press. Taylor \& Francis Group.

Hobday, R. (2016) Myopia and daylight in schools: a neglected aspect of public health? Perspectives in public health, $136: 1,50-55$

Lagréze, W.A., Schaeffel, F. (2017) Preventing myopia. Deutsches Ärzteblatt International, 114, 35-36, 575. DOI: $10.3238 /$ arztebl.2017.0575

\subsection{Individual experience}

In three experiments, it was tested whether the perceiver's emotions affected the perception of brightness. Brightness is one of the most important sources of perceptual information, as brightness differences provide contrast, which is essential for vision. These experiments provide evidence that perceiver's emotions can affect the perception of brightness in a metaphorically consistent manner; happy participants can judge the room to be brighter than sad participants (happy = brighter). The results have important implications for real-life scenarios, such as avoiding the undesirable effect of emotion on brightness perception in workshop scenarios.

To summarize, emotions influence not only individuals' feelings of personal well-being, but the physical nature of the environment around them.

The results of a field study in a Dutch office landscape showed that multiple confounders (general, environmental, and personal variables) were identified suggesting they should be taken into account when investigating the 
relationship between office lighting and human health. In addition, the initial relationship (excluding confounders) between Ehor and Subjective Alertness (SA) was established for six participants out of the total 46. Differences between the groups with and without the significant initial correlation between $E_{\text {hor }}$ and SA did not explain why certain individuals respond to changes in the lit environment and others do not. The current study demonstrated discrepancies between this field study and previously executed laboratory studies. The ability of 18 younger and older adults to visually perceive exocentric distances as evaluated. The judgements of the older observers were significantly more accurate than those of younger observers. The results show that increases in age can produce significant improvements in the visual ability to perceive the magnitude of exocentric distances.

The ability of 114 younger and older adults to recognize naturally-shaped objects was evaluated in three experiments. The visual recognition of natural object shape is different from haptic recognition in multiple ways: visual shape recognition can be superior to that of haptics and is affected by aging, while haptic shape recognition is less accurate and unaffected by aging.

Other researchers suggest that middle-aged adults' abilities to perceive and discriminate 3-D shape from motion are similar to those of younger adults. It appears, therefore, that the negative effects of increasing age do not become substantive until the age of 65-70 years.

\subsubsection{References}

Xiaobin Zhang, Bin Zuo, Kendall Erskine, Tao Hu. (2016) Feeling light or dark? Emotions affect perception of brightness. Journal of Environmental Psychology 47, 107-111.

J. van Duijnhoven, M.P.J. Aarts, A.L.P. Rosemann, H.S.M. Kort. (2018) Ambiguities regarding the relationship between office lighting and subjective alertness: an exploratory field study in a Dutch office landscape. Building and Environment 142, 130-138

Norman JF, Cheeseman JR, Adkins OC, Cox AG, Rogers CE, Dowell CJ, Baxter MW, Norman HF, Reyes CM. (2015) Aging and solid shape recognition: Vision and haptics. Vision Research 115, 113-118.

Olivia C. Adkins, Hideko F.Norman, Andrea G.Cox, Connor E.Rogers. (2015) Aging and the visual perception of exocentric distance. Vision Research 109, 52-58.

J. Farley Norman, Jacob R. Cheeseman, Jessica Pyles, Michael W. Baxter, Kelsey E. Thomason, Autum B. Calloway. (2013) The effect of age upon the perception of 3-D shape from motion. Vision research 93, 54-61

\subsection{Temporary and seasonal aspects}

Temporal context and adaptation profoundly affect visual perception. Despite the strength and prevalence of adaptation effects, their functional role in visual processing remains unclear.

The effects of spatial context to temporal context and their functional role are better understood: these effects highlight features that differ from their surroundings and determine stimulus salience. Similarities in the perceptual and physiological effects of spatial and temporal context raise the possibility that they serve similar functions.

For targets with small orientation offsets, adaptation reduced reaction times and decreased the number of saccades made to find targets. Results provide evidence that adaptation may function to highlight features that differ from the temporal context in which they are embedded.

In an experiment, researchers varied luminances of an approaching, light or dark disk and a plain, grey background, and for several conditions, continuously adjusted calibrations so as to keep contrast and/or overall lightness contrast. No effects were found, so the conclusion is that humans are able to discard luminance and contrast for the task at hand. The findings can be discussed with regard to implications for neural mechanisms, in the context of evolutionary considerations, and propose continuative animal behavioural studies.

\subsubsection{References}

Landwehr, K., Brendel, E., Hecht, H. (2013). Luminance and contrast in visual perception of time to collision. Vision Research 89, 18-23.

Wissig, S. C., Patterson, C. A., \& Kohn, A. (2013). Adaptation improves performance on a visual search task. Journal of Vision, 13(2):6, 1-15 http://www.journalofvision.org/content/13/2/6, doi:10.1167/13.2.6. 


\subsection{Typology and cultural differences}

Lighting design has direct relations on space perception, visual stimulus, spatial cognition and user behaviour in retail environments. Quantitative and qualitative perspectives in retail lighting design help to attract the customers play a role on the time spent in the retail environments, experience the built environment and displayed merchandise and create a suitable corporate identity. There is a connection between luminous environment perception, price perception and quality perception of displayed products in sales areas. The current research emphasizes the necessity of an appropriate lighting design strategy for retail environments and its impact on customer's space perception.

In a user study evaluating different lighting scenarios in scale models of retail environments different colour temperatures and brightness variations have been tested. It has been found that lighting scenarios with mixed colour temperatures of the light sources gave the highest perceived brightness ratings when cool-white light was used for accent light and warm-white light was used for ambient light. Zonal illumination was rated brighter than homogeneous illumination when cool-white light-sources were used.

Realistic lighting settings can have subtle effects on the perceived atmosphere and experienced emotions and lighting can be used to communicate a certain image.

Lighting can affect perception and emotion, but the behaviour is more difficult. Lighting in and by itself can communicate the image of a store environment.

The atmosphere perception of dynamic coloured lighting over warm and cool hue ranges was investigated in a living room with Dutch and Chinese observers. Experiments were carried out with eight fully functional tunable LED luminaires. Four-atmosphere factors were extracted: coziness, spaciousness, liveliness, and warmth. Both dynamics and the hue range of light significantly affected the atmosphere perception. Correlation analysis revealed the effects of lighting properties in atmosphere factors. High speed and chroma are helpful in the creation of liveness, while low speed and low chroma can increase coziness. The hue range also weighs high on atmosphere perception. Both cool hue range lighting and high luminances can produce spaciousness, which related to the attributes of alert, spatial and formal. The application of a warm hue range helps to create warmth as expected. Coziness is positively correlated with luminance. This is contrary to findings from some previous studies. Dynamic lighting and cultural differences (Dutch and Chinese) are possible reasons to explain the discrepancy.

An experiment has been carried out to investigate the effect of lighting on the perception of the atmosphere in a living room, using three types of light sources: halogen, fluorescent and LED lamps. In a psychophysical experiment, 29 native Chinese observers assessed eight lighting conditions having different luminances and correlated colour temperatures. For each condition, 71 scales were employed using the categorical judgment method. Factor analysis identified two underlying dimensions: liveliness and coziness. This agrees with those found by Vogels who used Dutch observers to assess atmosphere perception. Both observer groups also agreed that an increase of luminance would make the room livelier. However, there were also some disagreements such as a higher CCT source would make the room livelier for Chinese observers but less lively for Dutch observers.

The use of light to stage atmospheres in a residential area of Copenhagen, Denmark was explored. Both natural and electrical lights enable visibility, but they also impart a certain sense of place that influences the way people behave and feel. The investigation deals with how light is about more than individual perception and plays a crucial role in orchestrating a sense of community, solitude and 'secureness' at home. Such staging of atmospheres, it is argued, importantly relies on cultural premises and notions of intimacy, informality, and relaxation, encompassed in the Danish term hygge, or coziness. Light frames such a sense of secureness and coziness by allowing for visual oscillations between separation and connection of people, places and things. In this way, investigating the use of light in shaping atmosphere offers a lens to explore how connections and networks of people, emotions and things, shape the home and links interior and exterior spaces.

\subsubsection{References}

Bille, Mikkel. (2015) Lighting up cosy atmospheres in Denmark. Emotions, Space and Society $15,56-63$

B Li, QY Zhai, JB Hutchings, MR Luo and FT Ying. (2017) Atmosphere perception of dynamic LED lighting over different hue ranges. Lighting Research and Technology.; 51:5 682-703.

Feride Şener Yılmaz (2018) Human factors in retail lighting design: an experimental subjective evaluation for sales areas, Architectural Science Review, DOI: 10.1080/00038628.2018.1450725. 
Jan Vanrie, K.Q., Van Cleempoel, K. (2014) As real as it gets: What role does lighting have on consumer's perception of atmosphere, emotions and behaviour? Journal of Environmental Psychology 39, 2014, 32-39.

Staggl, S., Reiter, K., Ampenberger A. (2017), Visual, emotional and energy effects of a new lighting concept, Deliverable 4.9 of CommONEnergy, http://www.commonenergyproject.eu/resources/deliverables.html

XY Liu, , MR Luo, H Li. (2015) A study of atmosphere perceptions in a living room. Lighting Research and Technology. 47:5, 581-594.

\subsection{Overall conclusions}

\section{Vision development}

High daylight levels in spaces occupied by children are recommended (minimum 1\% D at children's permanent working places)

Long distance views through windows should be enabled from permanent work places.

Visual performance (speed and accuracy of processing visual information)

Daylight should be prioritized at workplaces demanding high level of visual performance, as it maintains alertness and physical well-being better that electric light.

Emotions affect the perception of brightness and therefore influence not only individuals' personal well-being but also the perception of physical environment around them, indirectly also performance.

Temporal context profoundly affects visual perception; the adaptation may function to highlight features that differ from the temporal context in which they are embedded. However, it must be underlined that humans are able to discard luminance level and contrast for the task at hand.

Cultural differences (Dutch - Chinese observers) were found regarding perception and emotion due to illumination. However, there are similarities in perception e.g. the increase of luminance makes the room livelier. 


\subsection{Glare from daylight}

Factors almost certainly influencing discomfort glare perception are the luminance of the glare source, adaptation level, contrast effect, and size and position of the glare source.

In a semi-controlled study in a test room with direct access to daylight and to an external view the influences detected showed a tendency towards an increasing tolerance to discomfort from daylight glare as the day progresses.

The factors that almost certainly do not influence discomfort glare perception are the gender and optical correction of the observer.

Other factors, such as the attractiveness of the view through the window or the culture of the observer, require additional studies to determine whether or not they influence discomfort glare perception.

There are several metrics used to determine glare from daylight. Daylight Glare Probability (DGP) is the metric most often used. However, DGP should not be used for spaces with horizontal openings (e.g. skylights) and in situations where vertical illuminance is expected not to be a good indicator for the glare perception, like dark spaces with small opening(s).

\subsubsection{References}

Clotilde Pierson, Jan Wienold \& Magali Bodart. (2018) Review of Factors Influencing Discomfort Glare Perception from Daylight LEUKOS 14, 111 - 148

Kent, M.G., Altomonte, S., Wilson, R. et al. (2017) Temporal effects on glare response from daylight. Building and Environment, 113, 49-64.

Jan Wienold and Jens Christoffersen. (2006) Evaluation methods and development of a new glare prediction model for daylight evironments with the use of CCD cameras. Energy and Buildings, 38, 542-757

Jakubiec JA., Reinhart CF. (2012) The 'adaptive zone' - A concept for assessing discomfort glare throughout daylit spaces. Lighting Research and Technology. 44, 149-170.

GH Scheir, M Donners, LM Geerdinck, MCJM Vissenberg MCJM, P Hanselaer, WR Ryckaert. (2018) A psychophysical model for visual discomfort based on receptive fields. Lighting Research and Technology, 50, 205- 217

McNeil, A. Burrell, G. (2016) Applicability of dgp and dgi for evaluating glare in a brightly daylit space. Proceedings of SimBuild, August 2016.

Wasilewski, S., Grobe, L.O., Wienold, J., Andersen, M. (2019) A Critical Literature Review of Spatio-temporal Simulation Methods for Daylight Glare Assessment. Journal of Sustainable Design \& Applied Research, Vol. 7.

\subsection{Glare from electric lighting}

Human behaviour is a good indication of glare. When the behaviour of users is to shield the eyes or look away, this is the indication of the presence of a very high luminance in the visual field, glare.

The metrics used to determine glare from electric lighting are the Visual Comfort Probability (VCP) system used in North America and the CIE Unified Glare Rating (UGR) system. Neither system considers the immediate surrounding.

UGR has been shown to fail to accurately predict peoples' levels of discomfort, particularly for LED sources. As a result, there is a vast development of new metrics to measure glare. 
Looking back, several types of methodological and analytical approaches have been associated with two procedures that have formed the basis of prediction models used to evaluate glare due to discomfort (luminance adjustment and category rating). The development and testing of new metrics should account for biases associated with the methods and analysis chosen for testing.

The results from the study of discomfort due to sources of glare in the peripheral visual field confirmed the hypothesis: a lower degree of discomfort was expressed in the pseudo-text trials than in trials with the circular fixation mark. The results demonstrate that the visual task influenced the evaluation of discomfort. When engaged in the pseudo-text task, participants were more tolerant to glare, seen as settings of higher luminance in the adjustment task and lower ratings of discomfort in the category rating task. The differences are statistically significant with a small, yet practically relevant, effect size. This change in discomfort may be due to differences in the degree of cognitive attention demanded by the visual task or to the ability of the task to maintain fixation and reduce glances toward the glare source.

Glare sensation varies with the time of day. A laboratory study showed a tendency towards greater tolerance to luminance increases in artificial lighting as the day progresses.

Additionally, the time interval between test sessions showed a direct relationship to the increased tolerance to artificial source luminance throughout the day. The temporal variation of glare response was found to be influenced by the difficulty in extracting information from the visual stimulus. Moreover, statistically significant and substantive evidence was detected of a direct effect of fatigue and caffeine ingestion, and an inverse influence of food intake, on reported glare sensation.

\subsubsection{References}

Sweater-Hickcox K, Narendran N, Bullough JD, Freyssinier J-P. (2013) Effect of different coloured luminous surrounds on LED discomfort glare perception. Lighting Research and Technology 45: 464-475.

PR Boyce PhD, A Wilkins, Dphil. (2018) Visual discomfort indoors. Lighting Research and Technology. First Published January 9, 2018 https://doi-org.zorac.aub.aau.dk/10.1177/1477153517736467

Y Yang, MR Luo and WJ Huang (2017) Assessing glare, Part 4: Generic models predicting discomfort glare of light-emitting diodes. Lighting Research and Technology, First Published 16 Mar 2017

Fotios, S. (2015) Research note: uncertainty in subjective evaluation of discomfort glare. Lighting Research and Technology; 47, 379-383.

Kent M, Fotios S, Altomonte S. (2017) Discomfort glare evaluation: the influence of anchor bias in luminance adjustments. Lighting Research and Technology. DOI: 1477153517734280.

Michael G. Kent, Steve Fotios, and Sergio Altomonte (2019) An experimental study on the effect of visual tasks on discomfort due to peripheral glare. LEUKOS 2019, 15:1, 17-28

https://doi.org/10.1080/15502724.2018.1489282

MG Kent, S Altomonte, PR Tregenza and R Wilson (2015) Discomfort glare and time of day, Lighting Research and Technology 47, 641-657

Sergio Altomonte, Michael G. Kent, Peter R. Tregenza, Robin Wilson. (2016) Visual task difficulty and temporal influences in glare response. Building and Environment 95, 209-226

\subsection{Contrast daylight}

Contrast is determined by the difference in the colour and brightness of the object and other objects within the same field of view.

The human visual system is more sensitive to contrast than absolute luminance, therefore humans can perceive the world similarly regardless of the huge disparities in illumination levels over the daytime and space

There are many concepts of luminance contrast metrics in terms of daylight, like Annual Spatial Contrast and Annual Luminance Variability. Due to the spatial impacts of light and shadow on our perception of contrast and the inherent variability of daylight as a source of illumination, Annual Spatial Contrast and Luminance Variability evaluate the compositional and temporal impacts of daylight on our perception of interior spaces. While Annual Spatial Contrast quantifies the sum of all local contrast boundaries across a given view, Annual Luminance Variability accounts for the total change in luminance levels over time. The method of visualization for these 
metrics combines a cumulative image with a complementary temporal map to identify when and where these dynamic variations occur. The crucial point is to understand and use them universally along to contribute to a more holistic analysis of daylit architecture with metrics that complement existing illumination and comfort-based performance criteria.

In the study investigating joint impact of façade geometry and associated sunlight patterns on occupant subjective perception and physiological responses the results reveal that façade and sunlight pattern geometry significantly influenced subjective responses for both context scenarios, while subsequent analyses showed differences mostly between the Irregular and Regular conditions, with the former being evaluated more positively. Façade and sunlight pattern geometry affected heart rate responses, but not skin conductance responses. In particular, participants showed a larger decrease in heart rate while exposed to the Irregular condition compared to the Blinds. Context scenarios influenced evaluations of interest and excitement.

Luminance-based measures are useful for evaluation of visibility of contours as well as shape and details of objects. The analytical comparison showed that the contrast measurement (calculated with the Weber formula), luminance ratio between average luminance of the object and average luminance of the background, mean of paired point luminance ratio (mean point LR) measurements around the contour of the object, and percentage of the invisible part of the contour are all good predictors for contour distinctness of the observed 3D objects.

\subsubsection{References}

Rockcastle, S., Amundadottir, ML. \& Andersen, M. (2016) Contrast measurements for predicting perceptual effects of daylight in architecture renderings. Lighting Research \& Technology, 49: 7, 882 - 903

Rockcastle, S. \& Andersen, M. (2014) Measuring the dynamics of contrast \& daylight variability in architecture: A proof-of-concept methodology Building and Environment 81, 320-333

Rockcastle, S., Amundadottir, ML. \& Andersen, M. (2013) Celebrating Contrast and Daylight Variability in Contemporary Architectural Design: A Typological Approach, Conference Proceedings of Lux Europa

Rockcastle, S. \& Andersen, M. (2012) Dynamic Annual Metrics for Contrast in Daylit Architecture, Proceedings of the 2012 Symposium on Simulation for Architecture and Urban Design. Society for Computer Simulation International

K.Chamilothori G.Chinazzo, J.Rodrigues, E.S.Dan-Glauser, J.Wienold, M.Andersen (2019) Subjective and physiological responses to façade and sunlight pattern geometry in virtual reality. Building and Environment 150, 144-155

Zaikina, V. Matusiak, B. Klockner, C.A (2015a) Luminance-based measures of Contour Distinctness of 3D objects as a Component of Light Modeling LEUKOS 11: 1, 31-45

Zaikina, V. Matusiak, B. Klockner, C.A (2015b) Luminance-based measures of Shape and Detail Distinctness of 3D objects as Important Predictors of Light Modeling LEUKOS 11: 4, 193-207

\subsection{Contrast electric light}

Contrast is related to threshold capabilities of the human visual system. Contrast is defined as the difference in luminance or colour that makes an object or an image distinguishable for the human eye. The higher the contrast, the easier it is to detect the targets

The luminance contrast of a target quantifies its visibility relative to its immediate background.

Luminous contrast metrics are many depending on threshold spatial, temporal, and colour characteristics.

Yet, there are at least six contrast metrics published in the literature, but none of them fully describes all contrast conditions and thresholds in relation to dynamic changes of contrast (colour, luminance) in the visual field caused by LED sources.

\subsubsection{References}

Tural, E., Tural, M. (2014) Luminance contrast analyses for low vision in a senior living facility: A proposal for an HDR image-based analysis tool. Building and Environment 81, 20-28 
Van de Perre, L., Hanselaer, P., Scheir, GH., Smet, K., Ryckaert, WR. (2016) Contrast metrics evaluation. In Proceedings of CIE 2016 "Lighting Quality and Energy Efficiency ". Melbourne, Australia: CIE, 70-78

Stokkerman,s M., Vogels, I., de Kort, Y. and Heynderic,. I. (2017) Relation between the perceived atmosphere of a lit environment and perceptual attributes of light. Lighting Research and Technology; 0: 1-15

Van de Perre, L., Ryckaert, W.R., Dujardin, M., Smet, K.A.G. (2018) Contrasts and Brightness Perception of Illumination Patterns in Physically-based Rendered Scenes. CIE Midterm Meetings and Conference on Smarter Lighting for Better Life.

\subsection{Flicker}

Flicker may be divided into two types. One that is visual, i.e. it is possible to detect the flickering light with the eyes, and the other which could be named subliminal i.e. the flickering light is not consciously detected by the human, but the brain is registering the flicker.

Flickering lights can be uncomfortable to look at and can induce seizures in observers with photosensitive epilepsy. Subliminal flicker may cause headache, and impaired cognitive performance. Temporal modulation of lighting at frequencies higher than the critical fusion frequency can affect human efficiency in diverse ways that are not understood.

Measures for flicker are needed and methods have been proposed. Today it is important to have measures since pulse width modulation for dimming the light output of LEDs has become common. These artefacts need to be avoided or at least reduced to a minimum in order to obtain high user acceptance.

\subsubsection{References}

Anstis, S. \& Rogers, B. (2012) Binocular fusion of luminance, colour, motion and flicker - Two eyes are worse. than one. Vision Research 53, 47-53

Bodington, D., Bierman, A. \& Narendran, N. (2016) A flicker perception metric. Lighting Research and Technology. 48, 624-641

Boyce, PR., \& Wilkins, AJ. (2018) Visual discomfort indoors. Lighting Research and Technology. 50: 98-114

Herrmann, CS. (2001) Human EEG responses to 1-100 Hz flicker: resonance phenomena in visual cortex and their potential correlation to cognitive phenomena. Exp Brain Res. 137: 346-353

Jaén, EM., Colombo, EM. \& Kirschbaum, CF. (2011) A simple visual task to assess flicker effects on visual performance. Lighting Research and Technology 43: 457-471

Knez, I. (2014) Affective and cognitive reactions to subliminal flicker from fluorescent lighting. Consciousness and Cognition 26, 97-104

Liu, M-x., Yan, Y., Xue, Q. \& Gong, L. (2015) The research and analysis of factors affecting Critical Flicker Frequency. Procedia Manufacturing, 34279 - 4286

Polin, D., Klir, S., Wagner, M. \& Khanh, TQ. (2017) Reducing the stroboscopic effects of LED luminaires with pulse width modulation control. Lighting Research and Technology, 49: 370-380

Wilkins, A., Veitch, J. \& Lehman, B. (2010) LED Lighting Flicker and Potential Health Concerns: IEEE Standard PAR1789 Update. IEEE Energy Convers Congr Expo 1, 171-178

Yoshimoto, S., Garcia, J., Jiang, F., Wikins, AJ, Takeuchi, T. \& Webster, M. (2017) Visual discomfort and flicker. Vision Research 138, 18-2

\subsection{Spatial frequencies}

In the spatial domain, one identified source of visual discomfort is when images have Fourier amplitude spectra that deviate from the natural (1/frequency, $1 / f)$ statistical characteristics of natural scenes, especially if they contain excess energy at the medium frequencies at which the visual system is most sensitive. 
Deviation from the statistics of natural images could cause discomfort because the visual system is optimized to encode images with particular statistics typical of natural scenes.

Psychological and physiological benefits of viewing nature have been extensively studied for some time. More recently it has been suggested that some of these positive effects can be explained by nature's fractal properties.

Research suggests that the responses to statistical and exact fractals differ and that the natural form of the fractal is important for inducing alpha responses, and indicator of a wakefully relaxed state and internalized attention.

\subsubsection{References}

O’Hare, L. \& Hibbard, PB. (2011) Spatial frequency and visual discomfort. Vision Research 51, 1767-1777

HägerhälI, CM., Laike, T. Küller, M, Marcheschi, E., Boydston, C. \& Taylor, RP. (2015) Human physiological benefits of viewing nature: EEG responses to exact and statistical fractal patterns. Nonlinear Dynamics, Psychology and Life Sciences, 19, 1-12

Fernandez, D. \& Wilkins, AJ. (2008) Uncomfortable images in art and nature. Perception, 37, 1098-1113

Wilkins, AJ. (2016) A physiological basis for visual discomfort: Application in lighting design. Lighting Research and Technology 48, 44-54

Hägerhäll, CM., Laike, T., Taylor, RP., Küller, M., Küller, R. \& Martin, TP. (2008) Investigations of human EEG response to viewing fractal patterns. Perception, 37, $1488-1494$

\subsection{Temporal changes}

Studies on load shedding have shown that rapid changes in illuminance (of the order of 10-100 Ix/s) suggest that illuminance can decline by up to $20 \%$ without being detected. With slower rates of change ( $1 \mathrm{~lx} / \mathrm{s}$ or less), greater reductions in illuminance may remain undetected, and acceptable.

In a study where the direct component of a direct-indirect luminaire was reduced by $2 \%$ of full output per minute, to a minimum $20 \%$ output, the effects were generally negative (a small negative effect on comfort and arousal). There was no effect on environmental satisfaction, or on any of the many task performance outcomes (typing, memory, creativity, anagram solving, vigilance).

Participants with personal control exposed to ramps were not found to be less negatively affected by the ramps than those without personal control.

Temporal changes of daylight in the exterior during a day can be slow or rapid. They are associated with intensity, spectral composition and light colour occurrence. These changes can be observed and are welcome by occupants of interiors. People have a good ability to adapt to intensity and colour variations of natural light. One of the important aspects of a healthy indoor environment is access to daylight and its daily changes. Generally, more blue and brighter light appears the first part of the day while relatively more red light with a low portion of shortwavelength light is in the last two hours before sunset.

\subsubsection{References}

Newsham, G. R., Donnelli, C., Mancini, S., Marchand, R. G., Lei, W., Charles, K. E. \& Veitch, J. A. (2006) The Effect of Ramps in Temperature and Electic Light Level on Office Occupants: A Literature Review and a Laboratory Experiment. Proceedings of the 2006 ACEEE Summer Study on Energy Efficiency in Buildings, Pacific Grove, California, pp. 4-252 to 4-264.

Newsham, G. R.; Mancini, S.; Veitch, J. A.; Marchand, R. G.; Lei, W.; Charles, K. E.; Arsenault, C. D. (2009) Control strategies for lighting and ventilation in offices: effects on energy and occupants. Intelligent Buildings International 1: 2, 101-121 https://doi.org/10.3763/inbi.2009.0004

S Chraibi, P Creemers, C Rosenkötter, EJ van Loenen, MBC Aries, ALP Rosemann. (2018) Dimming strategies for open office lighting: User experience and acceptance. Lighting Research and Technology online first: https://doi-org.zorac.aub.aau.dk/10.1177\%2F1477153518772154

Y Akashia, J Nechesb. (2005) Potential recommendations for illuminance reductions by load-shedding. Lighting Research and Technology 37:2, $133-153$ 
S Sanders. (ed.). (2017) Changing perspectives on daylight: Science, technology, and culture, Nature, attachment Washington: DC, AAAS.

\subsection{Colour of light, daylight}

Surface colour constancy is best for blue daylight illuminations, the illumination discrimination is also enhanced. The mechanisms of colour perception mediated by the phylogenetically older $(B-Y)$ colour pathway have been strongly influenced by the different phases of daylight.

Overall, there is a preference for daylight filtered through bronze window as opposite to the blue glazing. The glazing colour type may have a significant effect on the arousal level of office workers, the level of self-reported arousal decreased in the presence of the blue glazing.

A linear correlation was found between CCT and CRI for polymer dispersed liquid crystal (PDLC) glazing.

The angle selectivity of the glazing combined with its active switching effect allows a wide range of selectable transmission states to suit the latitude and orientation of a building in relation to the local climatic conditions. Especially for south facing windows and under the involved climatic conditions, EC glazing driven by a dynamic control strategy can be very effective in reducing discomfort glare caused by high window brightness.

Most of the users appreciate the manual operation of the EC system and do not wish for an automated control.

Higher transmittance glazing types (77\%-79\% oppose to $50 \%$ ) result in more positive ratings for factors, such as naturalness, beauty, and pleasantness and sharpness.

The smart glazing types studied with the human observers had a statistically significant negative impact on the perception of interior colours. The strongest impact registered was for reddish colours observed through an electrochromic glass in the low-transmit state (fully tinted).

\subsubsection{References}

Bradley Pearce et al. (2014) Human Colour Constancy is Optimised for Blue Daylight Illuminations. PLOS ONE www.plosone.org.

Athanasios Panorgias et al. (2012) Phases of daylight and the stability of colour perception in the near peripheral human retina. Journal of Vision 12(3)1, 1-11

Hélène Arsenault, Marc Hébert, Marie-Claude Dubois. (2012) Effects of glazing colour type on perception of daylight quality, arousal, and switch-on patterns of electric light in office rooms. Building and Environment, 56, 223-231

A. Ghosh, T.K. Mallick, (2015) Evaluation of colour properties due to switching behaviour of a PDLC glazing for adaptive building integration. Renewable Energy, 2018. 120, 126-133

A. Piccolo, A. Pennisi, F. Simone, (2009) Daylighting performance of an electrochromic window in a small scale test-cell. Solar Energy, 83, $832-844$

A. Piccolo, F. Simone, (2009) Effect of switchable glazing on discomfort glare from windows. Building and Environment, $44,1171-1180$

M-C Dubois, F. Cantin, K Johnsen (2007) The effect of coated glazing on visual perception: A pilot study using scale models. Lighting Research and Technology, 39:3, 283-304

Michele Zinzi (2006) Office worker preferences of electrochromic windows: a pilot study. Building and Environment 41, 1262-1273

S. Arbab et al. (2017) The impact of advanced glazing on colour perception. Journal of the International Colour Association 17, 50-68

\subsection{Colour of light, electric light}

Studies on user acceptance of Light-Emitting Diode (LED) lighting were largely done in developed countries, while there are presumably significant differences between the developed and developing countries. 
Series of measurements of various domestic LED lamps in Indonesia were conducted to investigate the effects of varying illuminance $\left(\mathrm{E}_{\mathrm{av}}\right)$, Correlated Colour Temperature (CCT), and Colour Rendering Index (CRI) on visual perception and to determine the users' preference of those parameters in the Indonesian context. Visual assessments were conducted using observation compartments in a dark room. The assessments have consisted of subjective performance and preference tests. The performance tests focused on the subjects' acuity in reading letters with various sizes and contrast; while the preference tests focused on the perception of lighting level, colour clarity, colour appearance, and overall visual comfort. It was found that variation of the CCT yields a significant effect on colour clarity and visual comfort. In terms of colour appearance, variation of the CCT yields more significant effect compared to $\mathrm{CRI}$, while illuminance gives no effect. On lighting level, a variation of both $\mathrm{E}_{\mathrm{av}}$ and CCT yields a more significant effect compared to CRI. Most of the participating subjects felt visually comfortable under the CCT of $6500 \mathrm{~K}$, average desktop illuminance of $350 \mathrm{~lx}$, and a higher CRI value.

When exposed to three different LED lamps and a fluorescent one, users preferred LED, especially a CCT of $4000 \mathrm{~K}$ over $6000 \mathrm{~K}$. The observers preferred the spectral power distributions (SPDs) under which they found the lighting environment to look brighter and more spacious. The observers' preferences showed that spatial brightness was affected both by illuminances and SPDs. However, there was no significant interaction between the illuminances and the SPDs.

The short-term chromatic adaptation study in India shows $6500 \mathrm{~K}$ is the least preferred CCT, and $4000 \mathrm{~K}$ is preferred for task-oriented activities such as reading and eating. Furthermore, subjects are unable to differentiate between $3000 \mathrm{~K}$ and $4000 \mathrm{~K}$ while performing non-task-oriented activities such as relaxing and watching TV.

\subsubsection{References}

Revantino et al. (2018) The effects of illuminance, colour temperature, and colour rendering of various existing light-emitting diode lamps on subjective preference and performance in Indonesia. Journal of Building Engineering 19, 334-341

MS Islam et al. (2015) User acceptance studies for LED office lighting: Lamp spectrum, spatial brightness and illuminance, Lighting Research \& Technology47:1, 54-79

Dugar, Amardeep M.; Agarwal, Dashak (2019) A pilot study assessing short-term chromatic adaptation preferences for correlated colour temperature in India. Light \& Engineering, 27:1,38-45

\subsection{Overall comfort preferences}

A large-scale study included field measurements and surveys of three large commercial office buildings that have been finished in the U.S. Each building utilized a differing type of shading strategy: automated blinds, electrochromic glazing, and roller shades, respectively. This paper reports findings from the measured physical data and the surveys, which were sent to each building to assess occupants' subjective visual comfort perceptions. In total, 5,031 surveys were sent to the three buildings, and 1,068 total occupants responded (a response rate of $21.2 \%)$. Key findings:

(1) Occupants who were more pleased with their access to daylight were also more likely to have a higher perceived level of productivity and a higher level of satisfaction.

(2) Occupants' self-reported satisfaction with their workspace significantly differed based on their distance to the window, and those closer to the perimeter of the building were more satisfied than those who sat further away from the windows, and

(3) The trend of negative responses from occupants in one of the buildings (i.e. a perceived gloominess, perpetual sense of an overcast sky, etc.) raises interesting design questions, as related to the use of electrochromic glazing. It is crucial that designers understand daylighting strategies, shading, and corresponding human perceptions of comfort.

A psychophysical experiment explored the independent and interacting effects of hue, saturation and luminance control resolutions on the usability of colour-tuneable lighting systems. Three usability criteria were used to evaluate these effects. Results showed that combinations of middle-range hue resolution and saturation resolution facilitated the greatest usability. When luminance control was independent of hue and saturation control, luminance resolution did not significantly impact usability. 
Julia K.Day, Benjamin Futrell, RobertCox, Shelby N.Ruiz (2019) Blinded by the light: occupant perceptions and visual comfort assessments of three dynamic daylight control systems and shading strategies, Building and Environment Available online 6 March 2019, https://doi.org/10.1016/j.buildenv.2019.02.037

Wenye Hu, Wendy Davies (2019) The effect of control resolution on the usability of colour-tunable lighting systems, LEUKOS, IES, 15:1, 3-16

\subsection{Overall conclusions}

\section{Glare from daylight}

Daylight Glare Probability is recommended in the scope of its usability for the estimation of glare in daylit spaces. It takes into account the luminance of the glare source, adaptation level (vertical illuminance), contrast effect, and size and position of the glare source.

The tolerance is higher for glare from daylight when compared to electric light. Glare from daylight is also slightly lower when the view is dominated by greenery and it increases with the time of the day. Therefore, the DGP should be used with care.

\section{Glare from electric lighting}

Human behaviour is a good indication of glare. When the behaviour of users is to shield the eyes or look away, this is the indication of the presence of a very high luminance in the visual field. The metrics used to determine glare from electric lighting are the Visual Comfort Probability (VCP) system used in North America and the CIE Unified Glare Rating (UGR) system. Unfortunately, neither system considers the immediate surrounding.

In addition to factors almost certainly influencing discomfort glare sensation, as the luminance of the source, adaptation level, contrast effect, and size and position of the glare source, the time of the day and the difficulty of the task should be considered.

\section{Flicker}

Flicker may be divided into visual and subliminal.

Due to increased opportunities with pulse width modulation for dimming the light output of LEDs, the measures of flicker became more important.

Flickers need to be avoided or at least reduced to a minimum in order to obtain high user acceptance.

\section{Spatial frequencies}

Repetitive contrasts patterns in medium frequencies at which the visual system is most sensitive should be avoided, e.g. luminance patterns made by shading devices with a strict geometrical design.

\section{Temporal changes}

Even though humans can easily adapt to light level changes in daylight, the daylight design should respect the dynamic of daylight level and view to colour of the sky.

Rapid changes in electric light level (higher than $2 \%$ of full output per minute) should be avoided.

\section{Colour of light, daylight}

Clear glazing giving undistorted light colour is favoured.

\section{Colour of light, electric light}

The observers prefer the spectral power distributions (SPDs) under which the indoor environment looks brighter and more spacious. Spatial brightness depends both on illuminance and SPD. Anyhow, for task-oriented activities $4000 \mathrm{~K}$ is preferred over $6000 \mathrm{~K}$. 


\section{Psychological aspects of light}

\subsection{Daylight versus electrical light}

In two realistic office lighting environments significantly higher visual acceptance scores under DL than EL conditions were found, despite of the lack of a direct outside view.

The subjective glare was lower under DL than under EL conditions.

While subjective alertness and physical well-being decreased for both lighting conditions in the course of the afternoon, subjects felt sleepy earlier under EL than DL.

Physical well-being became worse in the course of the afternoon only under EL. These variations were at least in part predicted by three different photometric variables (vertical illuminance, CCT and CRI) in the DL condition in the course of the afternoon.

The dynamics of physical well-being and subjective alertness during the afternoon were different: They both decreased relatively earlier under EL than DL (compared to noon values).

\subsubsection{References}

A Borisuit, F Linhart, J-L Scartezzini and M Munch (2015) Effects of realistic office daylighting and electric lighting conditions on visual comfort, alertness and mood, Solar Energy and Building Physics Laboratory, Ecole Polytechnique Fe' de' rale de Lausanne, Lausanne, Switzerland Lighting Research and Technology 2015 ; Vol. 47: 192-209

\subsection{Quality of the view out}

Research clearly shows the benefits of interesting and informative views for worker health, well-being and productivity.

The existing hypotheses and research findings about preferences for view may be categorized into three groups:
-the need for information about the outside environment,
-the need for aesthetic experience and
-the need for restoration and health.

The view quality evaluated by subjects (working in an office in a little town with much greenery outdoors) is best predicted by the view distance, the number of view layers, the quality of the landscape/elements and the composition of the view.

The new European standard EN17037 "Daylight in Buildings" also specifies (1) the size of the daylight opening(s), (2) the width of the view (horizontal sight angle), (3) the outside distance of view, (4) the number of layers, and (5) the quality of the environmental information of the view, as the main quality properties of the view out.

The view quality has impact on the perception of glare, especially the views toward greenery can reduce the glare from the windows.

It is advisable to separate the experience of this special view from the experience of the normal view of the visual task to be performed. Where possible, workstations should be placed in a way which directs the view of normal tasks at approximately right angles to the view out the window.

The mean luminance of a window, the type of window view, and the distance of the view objects should also be considered in the evaluation of the subjective discomfort glare from a window. 
The results on visual preferences with children indicated that young children are able to differentiate lighting needs according to the activity performed. Visual contact with the view seen through the classroom window was important to the children, with a higher preference for natural views.

\subsubsection{References}

Markus, T.A. (1967) The function of windows? A reappraisal Building Science 2 (2) 97-121

Kaplan, R. (1993) The role of nature in the context of the workplace Landscape and Urban Planning 26(1-4) 193201

Heschong, L. (2003) Windows and classrooms: A study of student performance and the indoor environment California Energy Commission

J. Granzier M. Valsecchi, (2014) Variations in daylight as a contextual cue for estimating season, time of day, and weather conditions Journal of Vision 14(1):22, 1-23

W. Osterhaus (2009) Design Guidelines for Glare-free Daylit Work Environments. Proceedings of LUX Europa 2009, $11^{\text {th }}$ European Lighting Congress, Istanbul, Turkey, 09-11 September 2009, page 431

Ju Young Shin, Geun Young Yun, Jeong Tai Kim (2012) View types and luminance effects on discomfort glare assessment from windows. Energy and Buildings 46 (2012) 139-145

B. Matusiak, Ch. A. Klöckner, (2015) How we evaluate the view out through the window. Architectural Science Review DOI: 10.1080/00038628.2015.1032879

Natalia Giraldo Vásquez; Maíra Longhinotti, Felippe Fernando O.R.Pereira, Ariane Kuhnen. (2019) Luminous and visual preferences of young children in their classrooms: curtain use, artificial lighting and window views. Building and Environment 152 59-73

CEN - European Committee for Standardization (2018), EN17017 Daylight in Buildings, European Standard.

\subsection{Privacy (lack of)}

In modern office buildings, an increasing number of employees and decreasing of individual space already has an impact on the efficiency and versatility of coping with stressful situations of the employees.

Apart from the stress induced by the lack of space and privacy, the light level is yet another important factor. Poor light or extreme illumination, or even more relevant, periodic shadow disturbance (i.e. windmills) are all increasing factors of stress levels. Control of illumination in a closed environment seems to be a feasible solution, but perhaps not very useful for the overall mood of the employee and possibility to see green patches, sunlight, have a significant positive influence on the overall working conditions.

Known or detectable, measurable hence predictable disturbances are important factors in designing advanced control strategies. Several possibilities exist: internal model control, predictive control, distributed control and game theory control.

\subsubsection{References}

Jasper Juchem, Stijn Lefebvre, Thi Thoa Mac Clara M. Ionescu (2018) An analysis of Dynamic Lighting Controll in Landscape Officies IFAC Papers on line 51:4, 232-237

\subsection{Perceived quality of interior space - daylight}

The impression of room dimensions depends on window form, even if the total glazing area is equal. Generally, vertical windows make that the room appears higher, horizontal make it wider. The window adjacent to a sidewall contributes to higher luminance of this wall, it appears as being further away from the observer; the room appears as wider. The same principle is true for windows adjacent to the ceiling or floor. They contribute to increasing the impression of height.

Separately, window size and room reflectance have statistically significant positive effects on the quality attributes: spaciousness, openness, spatial definition, pleasantness, excitement, legibility and coherence.

Both the daylighting systems and the type of sky have an effect on the aesthetic attributes, and the significant interaction effect suggested that the aesthetic perception of rooms with daylighting systems depends on the type 
of sky. The High Reflective Blinds was the daylighting system that scored highest in nearly all attributes under both clear and overcast sky conditions as compared to two types of light shelves and traditional venetian blinds.

The renovation of dwellings for energy efficiency impacts spatial quality by crossing technical measures of dwelling renovation with the definition of spatial quality. The results of this crossing are developed further into a spatial quality assessment which is the interaction between four determinants: (1) views, (2) internal spatiality and spatial arrangements, (3) transition between public and private spaces, and (4) perceived, built and human densities.

\subsubsection{References}

B. Matusiak (2006) The impact of window form on the size impression of the room. Full-scale studies. Architectural Science Review, 49: 1, 43 - 52.

B. Matusiak, B. Sudbø (2008) Width or Height? Which has the strongest Impact on the Size Impression of Rooms? Architectural Science Review, 51:2, 165 - 172.

C. Moscoso, B. Matusiak and P. Svensson, (2015) Impact of window size and room reflectance on the perceived quality of a room, Journal of Architectural and Planning Research 32:4 (Winter, 2015) 294

C. Moscoso, B. Matusiak (2017) Aesthetic Perception of a Small Office with Different Daylighting Systems. 2017, Indoor and Built Environment, DOI: 10.1177/1420326X17711490

Fernanda Acre, Annemie Wyckmans (2015) Dwelling renovation and spatial quality. The impact of the dwelling renovation on spatial quality determinants, International Journal of Sustainable Built Environment (2015) 4, 12-41

\subsection{Perceived quality of interior space - electric light}

Daylight plays a smaller role than electric light on the perception of light and atmosphere in a space when the luminance of daylight is controlled and there is no view outside. This study demonstrated that increasing the light's brightness may increase coziness, liveliness, and detachment; cooler light may decrease coziness and increase detachment; and more uniform light may decrease tenseness and increase detachment.

In a field study involving 57 clothing stores, lighting attributes (e.g. brightness, contrast, glare and sparkle) and context (i.e. the shop's interior) were assessed and quantified independently. These data were then used to predict four dimensions of the perceived atmosphere (coziness, liveliness, tenseness and detachment). Brightness significantly and substantially decreased perceived coziness and increased perceived tenseness. Glare and sparkle contributed to the perceived liveliness of fashion stores. Furthermore, the shops' legibility was shown to significantly decrease perceived liveliness and increase perceived detachment.

The impression of a space depends hugely on the light in the space, more specifically on the intensity, colour, beam shape and position of the light sources in that space. Employing high-quality visualizations, it was found that atmosphere perception (coziness, liveliness, tenseness and detachment) can be accurately described by a second-order polynomial as a function of the two perceptual light attributes: perceived uniformity and brightness.

29 native Chinese observers assessed eight lighting conditions having different luminances and CCT. For each condition, 71 scales were employed using the categorical judgment method. Factor analysis identified two underlying dimensions: liveliness and coziness. This agrees with those found by Vogels who used Dutch observers to assess atmosphere perception. Both observer groups also agreed that an increase of luminance would make the room livelier. However, there were also some disagreements such as a higher CCT source would make the room livelier for Chinese observers but less lively for Dutch observers.

\subsubsection{References}

M. Stokkermans et al. (2018) A Comparison of Methodologies to Investigate the Influence of Light on the Atmosphere of a Space. LEUKOS 14:3, 167-191,

PJM Custers, Y. de Kort, WA IJsselsteijn and ME de Kruiff (2010) Lighting in retail environments: Atmosphere perception in the real world, Lighting Research and Technology 42:3, 331-343.

M Stokkermans, I Vogels, Y de Kort I Heynderick (2017) Relation between the perceived atmosphere of a lit environment and perceptual attributes of light. Lighting Research and Technology 50:8, 1164-1178 
XY Liu, MR Luo and H Li (2014) A study of atmosphere perceptions in a living room, Lighting Research and Technology 47:5, 581-594

\subsection{Behavioural effects of light - daylight}

Most people prefer to follow a daylight cycle instead of a constant level. Preferred lighting levels are significantly higher than today's indoor lighting standards and correspond to levels where biological stimulation can occur. The results strongly suggest that meeting biological lighting needs is very different from meeting visual needs. Results of two permanent occupants show striking differences in lighting settings, which correspond to individual circadian cycles and performance. This strengthens that present indoor lighting levels (and standards) are too low for biological stimulation. It has to be mentioned that results from studies investigating preferred light level gives different results depending on the used methodology.

The effects of daylighting in coordination with visual comfort, on university library users were measured in relation to four environmental processes, namely privacy, personal space, territoriality, and crowding. It was found that daylight and the four environmental processes are related.

Intermediate light switch probability by users was defined as a function of current illuminance levels, i.e. the probability for a given time step that the user will switch on or off the electric lighting, excluding such actions that happen upon user entry to or exit from the office. We assume such a probability to be independent of the user's history and further derive some theoretical consequences of this postulate.

To predict the impact of the six design parameters on pupil's learning progression. Comparing the "worst" and "best" classrooms in the sample, these factors alone were found to have an impact that equates to the typical progress of a pupil over one year. It was also possible to estimate the proportionate impact of these built environment factors on learning progression, in the context of all influences together. This scaled at a $25 \%$ contribution on average, where lighting was the most important of the six parameters.

Considerable proportions of students choose to work or sit near windows, the chief factor being the amount of daylight. View content (information and nature) are important, as well as visual and thermal comfort.

\subsubsection{Reference}

S.H.A. Begemann et al. (1997) Daylight, artificial light and people in an office environment, overview of visual and biological responses. International Journal of Industrial Ergonomics 20 231-239

Didem Kan Kilic, Deniz Hasirci, (2011) Daylighting Concepts for University Libraries and Their Influences on Users' Satisfaction, The Journal of Academic Librarianship 37: 6, 471-479

David Lindelo, Nicolas Morel, (2006) A field investigation of the intermediate light switching by users. Energy and Buildings 38, 790-801

Peter Barrett et al. (2013) A holistic, multi-level analysis identifying the impact of classroom design on pupils' learning. Building and Environment 59, 678-689

SMM Shemirani et al. (2011) Investigating the Behaviours of the Elementary School Students in Reference to Factors Associated with Daylight, Asian Social Science 73

\subsection{Behavioural effects of light - electric light and daylight}

Interactions with windows and lights are driven by both time-related events (entrance - departure) and environmental factors as outdoor and indoor temperature or workplace illuminance. A comparison of the proposed models with others developed for different climate zones suggests that interactions with windows are affected by the geographic area, while light switching behaviour seems to be very similar for the different case studies.

The variables identified to affect optimal lighting use in the hospital were: satisfaction with lighting, a subscale measuring attitudes (i.e. affective-related beliefs), and general lighting-use behaviours. The design of the interfaces also had an effect on lighting use.

Consumers tend to choose less healthy food options when ambient lighting is dim (vs. bright). Process evidence suggests that this phenomenon occurs because ambient light luminance influences mental alertness, which in turn influences food choices.

High satisfaction with the daylit work environment and positive effect of the horizontal shading strategy. 
Based on objective measurements and subjective data obtained in two field studies, users can be profiled based on their control behaviour, regarding characteristics as activeness, dominance, lighting tolerance, and dimming level preference. The results show significant differences between lighting preference profiles of users. This paper also proposes a first method for discovering and triggering submissive users to express their preferences in order to derive their profiles as accurately as possible.

For specific buildings user behaviour should be assessed in more detail, to allow the building design to be optimized for the actual user and its peculiarities. A guideline supports the decision process.

In a study with 100 subjects an artificial skylight providing a virtual view out and mimicking daylighting outperformed the electric lighting reference situation. The subjects felt more connected to the nature and perceived the windowless test room as more "lively," and less "tense" and "detached" under the artificial skylight than fluorescent illumination. Furthermore, under artificial skylight, subjects reported lower feelings of tension, anxiety, and claustrophobic symptoms, and a higher positive mood state. Also, subjects made riskier as well as more selfish decisions under artificial skylight.

\subsubsection{References}

Federica Naspi et al. (2018) Experimental study on occupants' interaction with windows and lights in

Mediterranean offices during the non-heating season. Building and Environment 127, 221-238

Pimkamol Maleetipwan-Mattsson, Thorbjorn Laike, Maria Johansson (2016) Factors affecting optimal lighting use in shared hospital environments: A case-study. Building and Environment 96, 260-269.

Biswas, D. at al. (2017) Shining Light on Atmospherics: How Ambient Light Influences Food Choices Journal of Marketing Research ISSN: 0022-2437 (print) Vol. LIV, 111-123

Ying Hua, Anne Oswald, Xiaodi Yang (2011) Effectiveness of daylighting design and occupant visual satisfaction in a LEED Gold laboratory building Building and Environment 46, 54-64

Marija Despenic et al. (2017) Lighting preference profiles of users in an open office environment Building and Environment 116, 89-107

P. Hoes (2009) User behaviour in whole building simulation Energy and Buildings 41, 295-302

Canazei M, PohI W, Bliem HR, Martini M, Weiss EM (2017). Artificial skylight effects in a windowless office environment. Building and Environment, 124: 69-77.

\subsection{Psychological processes influencing lighting quality}

Veitch and Newsham proposed a behaviourally-based model for lighting quality research, in which individuallybased processes mediate the relationships between luminous conditions and such behavioural outcomes as task performance, mood, social behaviour, aesthetic judgements and satisfaction.

This review paper summarizes the state of knowledge concerning mediating psychological processes:

- perceived control,

- attention,

- environmental appraisal, and

- affect.

\section{Reference}

Jennifer A. Veitch (2001) Psychological Processes Influencing Lighting Quality Journal of the Illuminating Engineering Society 30:1 


\subsection{Overall conclusions}

\section{Daylight versus electrical light}

In general, people prefer daylight compared to electrical light. If possible, they choose to sit by the windows with daylight and view out. Physical well-being, subjective glare and subjective alertness have been shown to decrease earlier in a room illuminated by electric light compared to daylight, despite the luck of the view out.

\section{Quality of the view out}

People should have access to windows giving good view out in terms of information about the outdoors, restoration from tiredness or stress and, preferably, aesthetical experience, especially from rooms for permanent use.

\section{Perceived quality of interior space - daylight}

The size of windows should not be minimized as this not only limit the view, but also has negative effect at the perceived quality of the space, specifically on: spaciousness, openness, spatial definition, pleasantness, excitement, legibility and coherence.

\section{Perceived quality of interior space - electric light}

Lighting has clear impact on the two underlying dimensions: liveliness and coziness of the space. The increase of luminance makes the space appear livelier. Regarding the CCT, regional differences were found, such as a higher CCT source would make the room livelier for Chinese observers but less lively for Dutch observers.

\section{Behavioural effect of light}

Most people prefer to follow a daylight cycle instead of a constant level of light. Preferred lighting levels are significantly higher than today's indoor lighting standards and correspond to levels where biological stimulation can occur.

It was found that daylight is related to four environmental processes namely privacy, personal space, territoriality, and crowding.

Good holistic lighting, together with five others design parameters, has significant effect on pupil's learning progression.

It was even shown that people prefer rooms with virtual daylight openings over rooms without perceived connection to the outside. 


\subsection{On ipRGCs action spectrum and the other receptors}

The ipRGC is not the only photoreceptor that has an impact on photo entrainment. Both rods and the three different types of cones seems to influence the photo entrainment. However, the effect of ipRGC is very strong. As a consequence, a spectral distribution where all wave-lengths are represented seems to be important.

For the first time, the existence of a close relationship between the circadian system robustness and the pupillary reflex response has been demonstrated, two non-visual functions primarily under melanopsin-ipRGC input.

From a methodological point of view new knowledge about the circadian system among different species has an impact on our understanding. Today we know that there at least five different types of ipRGC in mice and in rats. It seems that melanopsin is likely the photopigment of all rat ipRGC. However, there are also differences between mice and rats. It is suggested that the difference between rat and mouse could explain difference in photoentrainment threshold between mouse and other species.

The new knowledge about the different photoreceptors identifies a problem regarding measurement. Lucas et al (2014) points out the necessity for more elaborate measurement of light. They propose methods of light measurement that quantify effective irradiance for each of the photoreceptive inputs to the system.

\subsubsection{References}

Altimus, CM., Güler, AD., Alam, NM., Arman, C., Prusky, GT., Sampath, AP. \& Hattar, S. (2010) Rod photoreceptors drive circadian photoentrainment across a wide range of light intensities. Nature Neuroscience 13, 1107-1113

Bonmati-Carrion MA, Hild K, Isherwood C, Sweeney SJ, Revell VL, Skene DJ, Rol, MA. \& Madrid, JA. (2016) Relationship between Human Pupillary Light Reflex and Circadian System Status. PLOS ONE 11(9): e0162476. doi:10.1371/journal.pone.0162476

Brainard, GC., Sliney, D., Hanifin, JP., Glickman;G., Byrne, B., Greeson, JM., , S., Gerner, E. \& Rollag, MD. (2008) Sensitivity of the Human Circadian Systemto Short-Wavelength (420-nm) Light. Journal of Biological Rhythms, 23, 379-386

Cui, Q., Ren, C., Sollars, PJ., Pickard, GE. \& So, K-F. (2015) The Injury Resistant Ability of MelanopsinExpressing Intrinsically Photosensitive Retinal Ganglion Cells - Neuroscience Forefront Review. Neuroscience 284, 845-853

Lall, GS., Revell, VL., Momiji, H., Al Enezi, J., Altimus, CM., Güler, AD., Aguilar, C., Cameron, MA., Allender, S., Hankins, MW. \& Lucas, RJ. (2010) Distinct Contributions of Rod, Cone, and Melanopsin Photoreceptors to Encoding Irradiance. Neuron, 66, 417-428

Lucas, RJ., Peirson, SN., Berson, DM., , TM., Cooper, HM., Czeisler, CA., Figueiro, MG., Gamlin, PD., Lockley, SW., O’Hagan, JB., Price, LL,. Provencio, I., Skene, DJ. \& Brainard, GC. (2014) Measuring and using light in the melanopsin age. Trends in Neurosciences 37, 1-9

Rao, F., Chan, AHS. \& Zhu, X. (2017) Effects of photopic and cirtopic illumination on steady state pupil sizes. Vision Research, 137, 24-28

Reifler, AN., Chervenak, AP., Dolikian, ME., Benenati, BA., Meyers, BS., Demertzis, ZD., Lynch, AM.,., Li, BY., Wachter, RD., Abufarha, FS., Dulka, EA., Pack,W., Zhao, X. \& Wong, KY. (2015) The rat retina has five types of ganglion-cell photoreceptors. Experimental Eye Research 130 17-28

Stabio, ME., Sabbah, S., Quattrochi, LE., Ilardi, MC., Fogerson, M., Leyrer, ML., Kim, MT., Kim, I., Schiel, M., LE., Renna, JM., Briggman, KL. \& Berson, DM. (2018) The M5 Cell: A Colour-Opponent Intrinsically Photosensitive Retinal Ganglion Cell. Neuron, 97, 150-163 
Tosini, G., Ferguson, I. \& Tsubota, K. (2016) Effects of blue light on the circadian system and eye physiology. Molecular Vision; 22, 61-72

\subsection{Hormones}

The most studied hormones in relation to non-image forming aspects of light are melatonin and glucocorticoids such as cortisol.

In a review by Posadziki et al. (2018) it is concluded that there are a great number of studies evaluating the effects of melatonin on health. In general, effects of melatonin have been shown to be associated with a wide variety of health outcomes in clinically and methodologically heterogeneous populations.

Evidence is accumulating regarding the importance of circadian core oscillators, several associated factors, and melatonin signaling in the maintenance of health. Dysfunction of endogenous clocks, melatonin receptor polymorphisms, age- and disease-associated declines of melatonin likely contribute to numerous diseases including cancer, metabolic syndrome, diabetes type 2, hypertension, and several moods and cognitive disorders.

Accumulating evidence suggests that the stress system is intimately related to the circadian clock system, with dysfunction of the former resulting in dysregulation of the latter and vice versa.

\subsubsection{References}

Hardeland, R. (2013) Chronobiology of Melatonin beyond the Feedback to the Suprachiasmatic NucleusConsequences to Melatonin Dysfunction. International Journal of Molecular Sciences, 14, 5817-5841

Hardeland, R., Madrid, JA., Tan, D-X \& Reiter, RJ. (2012) Melatonin, the circadian multioscillator system and health: the need for detailed analyses of peripheral melatonin signaling. Journal of Pineal Research, 52, 139-166

Nicolaides, NC., Charmandari, E. Kino, T. \& Chrousos, GP. (2017) Stress-Related and Circadian Secretion and Target Tissue Actions of Glucocorticoids: impact on Health. Frontiers in Endocrinology, 8:70. doi: 10.3389/fendo.2017.00070

Posadziki, PP., Kyaw, BM., Roberts, NJ., Brzezinski, A., Chrisopoulos, GI., Divaka, U. Bajpai, S., Soljak, M., Dunleavy, G., Jarbrink, K. Khaing Nang, EE., Kiong Soh, C. \& Car, J. (2018) Melatonin and health: an umbrella review of health outcomes and biological mechanisms of action. BMC Medicine 16:18 DOI $10.1186 / \mathrm{s} 12916-017-1000-8$

\subsection{Timing and previous exposure}

We must divide the non-image forming effects of light into two: long-term and acute effects. Furthermore, the previous exposure to light with certain spectral composition and intensity is also of great importance. In order to understand the impact, it is therefore of outmost priority to control both these aspects.

Direct, acute effects of light on alertness when increasing the intensity of polychromatic white light has been found to increase subjective ratings of alertness in a majority of studies, though a substantial proportion of studies failed to find significant effects. The effect of the colour temperature of white light on subjective alertness is less clear.

Prior light exposure influences the sensitivity of the ipRGCs, which may explain the increased response at the beginning of light exposure and results showing that the human circadian system is capable of integrating several hours of multiple exposures to short intermittent light pulses spaced by exposures to darkness.

Better powered studies are needed, especially studies that allow for the construction of dose-response curves, although there are interesting proposals.

The phase-response curves presented until now are consistent in showing that light exposures in the late evening phase-delays the circadian clock and light exposures in the late night and early morning phase advances the circadian clock.

\subsubsection{References}

Najjar, RP. Zeitzer, JM. (2016) Temporal integration of light flashes by the human circadian system. Journal of Clinical Investigation, 126, 938-947 
Smith MR, Revell VL and Eastman Cl. (2009) Phase advancing the human circadian clock with blue- enriched polychromatic light. Sleep med, 10, 287-294

Souman, JL., Tinga, AM., te Pas, SF., van Eeb, R. \& Vlaskamp, BNS. (2018) Acute alerting effects of light: A systematic literature review, Behavioural Brain Research, 337, 228-239

Wong KY, Dunn FA and Berson DM. (2005) Photoreceptor adaption in intrinsically photosensitive retinal ganglion cells. Neuron, 48, 1001-1010

\subsection{Individual differences}

There are differences related to chronotype, age and gender. There are also changes in chronotype over time. Girls and women seem to be significantly more morning oriented than boys and men. Younger children are more morning oriented and become rapidly evening oriented during puberty, while the more attenuated turn towards morningness occurs from the age of 20 years. Then from the ages 25 to 30 morningness-eveningness remains rather stable.

Elderly people display a higher risk for disturbed circadian rhythm. One of the possible causes of disturbed circadian rhythms and sleep in the elderly may be impaired photic input to the circadian clock. Age-related changes in lens density are known to reduce the transmission of short-wavelength light, which has been shown to be most effective in suppressing nocturnal melatonin. Also, changes in the neurophysiological pathways may be of importance.

Adolescents living in brightly illuminated urban districts had a stronger evening-type orientation than adolescents living in darker and more rural municipalities. This result persisted when controlling for time use of electronic screen media, intake of stimulants, type of school, age, puberty, time of sunrise, sex, and population density.

\subsubsection{References}

Hastings Hagenauer, M. \& Lee, TM. (2012) The neuroendocrine control of the circadian system: Adolescent chronotype Frontiers in Neuroendocrinology 33, 211-229

Herljevic, M., Middleton, B., Thapan, K. \& Skene, DJ. (2005). Light-induced melatonin suppression: age-related reduction in response to short wavelength light. Experimental Gerontology 40, 237-242

Knez, I. \& Kers, C. (2000). Effects of Indoor Lighting, Gender, and Age on Mood and Cognitive Performance. Environment and Behaviour, 32, 817-831

Randler, C. (2007). Gender differences in morningness-eveningness assessed by self-report questionnaires. A meta-analysis. Personality and Individual Differences, 43, 1667-1675

Randler, C., Freyth-Weber, K., Rahafar, A., Florez Jurado, A. \& Kriegs, JO. (2016). Morningness-eveningness in a large sample of German adolescents and adults. Heliyon 2 e00200

Roenneberg, T. Wirz-Justice, A. \& Merrow, M. (2003). Life between Clocks: Daily Temporal Patterns of Human Chronotypes. Journal of Biological Rhythms, 18, 80-90

Vollmer, C., Michel, U., \& Randler, C. (2012) Outdoor Light at Night (LAN) Is Correlated with Eveningness in Adolescents. Chronobiology International, 29, 502-508.

\subsection{Mood, SAD and sub-SAD}

Seasonality is a term for describing the degree of seasonal changes in mood and behaviour. Seasonal affective disorder (SAD) is defined as a recurrent pattern of major depressive episodes during winter and remission of symptoms in the summer, in the absence of seasonal psychosocial stressors' in the DSM-IV (Diagnostic and Statistical Manual of Mental Disorders, Fourth Edition). When comparing the prevalence as a function of latitude the authors found that the prevalence of SAD was higher in North America than in Europe. Moreover, the literature showed a positive correlation between the prevalence of SAD and latitude in North America. The general correlation between prevalence of SAD and latitude was generally weak and that other consideration for example climate, social and cultural context, and genetic vulnerability may play a more important role. 
Changes in day-length, shift-work, and transmeridian travel lead to mood alterations and cognitive function deficits. Sleep deprivation and circadian disruption underlie mood and cognitive disorders associated with irregular light schedules. Whether irregular light schedules directly affect mood and cognitive functions in the context of normal sleep and circadian rhythms remains unclear.

Also, effects of different light spectra on shift-work were shown: polychromatic white light with reduced short wavelengths, fulfilling current lighting standards for indoor illumination, may have a positive impact on cardiac physiology of night-shift workers without detrimental consequences for cognitive performance and alertness.

Given the existence of chronobiological disturbances in depression and evidence regarding their treatment in improving depression, a chronobiological approach, including timely use of light and melatonin agonists, could complement the treatment of the major depressive disorder.

\subsubsection{References}

Golden, RN., Gaynes, BN., Ekstrom, RD., Hamer, RM., Jacobsen, FM., Suppes, T., Wisner, KL. \& Nemeroff, CB. (2005) The Efficacy of Light Therapy in the Treatment of Mood Disorders: A Review and Meta-Analysis of the Evidence. American Journal of Psychiatry, 162, 656-662

LeGates, TA., Altimus, CM., Wang, H., Lee, H-K., Yang, S., Zhao, H., Kirkwood, A., Weber, ET., Hattar, S. (2012). Aberrant light directly impairs mood and learning through melanopsin-expressing neurons. Nature, 491, 594-598

Lewy AJ, Lefler BJ, Emens JS, et al. (2006) The circadian basis of winter depression. PNAS, 103, 7414- 7419

Ospri, LL., Prusky, G. \& Hattar, S. (2017) Mood, the Circadian System, and Melanopsin Retinal Ganglion Cells. Annual. Review of Neuroscience, 40, 539-56

Valdés-Tovar, M., Estrada-Reyes, R., Solis-Chagoyáni, H., Arguetal, J., Dorantes-Barrón, AM., QueroChávez, D., Cruz-Gardunol, R., Cercós, MG., Truet, C., Oikawa-Sala, J., Dubocovich, ML. \& Benitez-King, G. (2018) Circadian modulation of neuroplasticity by melatonin: a target in the treatment of depression. British Journal of Pharmacology, 175, 3200-3208

Zaki, NFW., Spence, DW., BaHammam, AS., Pandi Perumal, SR., Cardinalis, DP \& Brown, GM. (2018). Chronobiological theories of mood disorder. European Archives of Psychiatry and Clinical Neuroscience, 268, 107-118

Canazei M, PohI W, Bliem HR, Weiss EM (2017). Acute effects of different light spectra on simulated night-shift work without circadian alignment. Chronobiology International, 34(3): 303-317.

\subsection{Application}

In order to apply the new knowledge, there is a need of new measures regarding the non-image forming aspects of light. There are attempts to meet this need. For example, Rea \& Figueiro (2018) concludes that: "the circadian stimulus metric (a) was developed from several lines of biophysical research, including those from basic retinal neurophysiology; (b) has been validated in several controlled experiments; and (c) has been used successfully in a number of real-world applications. Any discussions of new metrics should take each of these foundational points into consideration".

The CIE proposes the $\alpha$-opic equivalent daylight (D65) illuminance ( $\alpha$-opic EDI) as a measure for evaluating the non-image forming effects of light in their standard "CIE System for Metrology of Optical Radiation for ipRGCInfluenced Responses to Light".

Daylight is the primary stimulus for synchronizing the human circadian photobiological system. Deficiency of daylight or its spectral anomaly in indoor environments is related to several health problems such hormonal unbalance, sleep disorder, depression and so on. In the light of new knowledge about the non-visual influence of light on humans, it is necessary to re-evaluate a number of the requirements and criteria of designing a healthy indoor environment.

There are also applications related to the lack of darkness which is also a very important factor for reducing adverse effects on the circadian rhythm. Light-emitting E-books may have a negative impact since they phase- 
delays the circadian clock, acutely suppresses melatonin and has important implications for understanding the impact of such technologies on sleep, performance, health, and safety.

The ambient light depending on the wall colours may influence the light input. One study found that even modest renovations like painting the space a lighter colour have a noticeable impact on the light received by a moving sensor.

Complete darkness is optimal for sleep and blue light should be avoided during the sleep opportunity.

\subsubsection{References}

Andersen, M., Gochenour, SJ. \& Lockley, SW. (2013) Modelling 'non-visual' effects of daylighting in a residential environment. Building and Environment 70,138-149

Caddicka, ZA., Gregorya, K. Arsintescua, L. Flynn-Evans, EE. (2018) A review of the environmental parameters necessary for an optimal sleep environment. Building and Environment, 132, 11-20

Chang, A-M., Aeschlbach, D., Duffy, JF. \& Czeisler, CA. (2014) Evening use of light-emitting eReaders negatively affects sleep, circadian timing, and next-morning alertness. Proceedings of the National Academy of Sciences, 112, 1232-1237

Hraska, J. (2015). Chronobiological aspects of green buildings daylighting. Renewable Energy, 73, 109-114

Rea, MS. \& Figueiro, M. (2018). Light as a circadian stimulus for architectural lighting. Lighting Resarch and Technology, 50, 497-510

CIE (2018) CIE System for Metrology of Optical Radiation for ipRGC-Influenced Responses to Light, CIE S 026/E:2018, CIE Central Bureau, Vienna.

\subsection{Overall conclusions}

- Non-image forming effects of light exists.

- Theoretical biological based valid models have been developed.

- Development of molecular endocrine knowledge develops fast and may change the models.

- Knowledge of the physiology and neuro-physiology of the eye and the neurological pathways develop rapid and must not be neglected.

- New metrics including non-image forming aspects of light are needed for the application of the new knowledge

- The importance of daylight should be stressed as the need for darkness.

- $\quad$ More needs to be known of the impact of different spectral composition of light sources

- When investigating human environments in relation to non-image forming aspects of light both daylight and electrical lighting must be taken into consideration

- $\quad$ Concerning research: Field studies need to reach higher levels of quality, and more meta-studies are needed in order to develop reliable and valid guidelines.

The time of exposure to bright light should be made in accordance with circadian system of users. 


\section{Conclusions}

The aim of the present report was to find out what needs people have for both daylight and electrical lighting and how this could be measured. We have considered the concept of lighting quality, which expresses the human perspective in lighting, and argued for extending its scope by adding non-image forming effects as well as psychological effects. We have structured the needs into four different groups related to the present understanding of the lighting quality concept.

In order to be able to investigate the quality of light in an environment there is a need for measures, although it is difficult to quantify quality. We have also added a table, Table 1, where measures are described. This list is not complete, and more metrics are needed, but we included most measures that are available at the moment and specified the recommended threshold values.

Starting with visual perception, the amount of light is of crucial importance, but we must be aware of that different humans have different needs. Especially in relation to energy saving for electrical lighting we should be aware of this. Certain groups need less light and certain groups need more. It is important to have the possibility to choose the individual preferred level. It must be possible to adapt the lighting situation to the single user. Furthermore, the daylight should be prioritized at workplaces demanding high level of visual performance, as it maintains alertness and physical well-being better than electric light. For children the possibility for long distance view, i.e. a view out, should always be taken into account since it has been shown that long distance view may help in avoiding myopia. To summarize, the illuminance levels should be related to the individuals and their individual needs, the lux levels in standards and building regulations should be taken as guidance, not as a target. We already have standards for different types of work situations, but we should add the individual demands for different groups and even individuals.

Concerning the visual comfort, the most prominent problem regarding both daylight and electrical lighting is glare. However, the tolerance of daylight glare is higher than for electrical lighting. Different measures should be used for those two types of light sources and used with care. The glare measure for electrical lighting is also problematic but could be used as a reference. The time of day and task difficulty must be also taken into consideration. Flicker, both visual and subliminal must be avoided. Where the limits for flicker should be drawn is not clear, but measures have been proposed. We should also consider that there are individual differences in the sensitivity for flicker. Young people are more sensitive and also people with neuropsychiatric disorders. Recent work suggests measures that are useful.

Relating to the comfort is also the colour of light. For daylight it has been shown that distorting coloured glazing has a negative impact on the visual comfort. When looking at the colour temperature of electrical lighting there are large cultural differences, but colour temperatures higher than $6000 \mathrm{~K}$ seems to be negative. The temporal changes also play a role, but temporal changes of daylight seem to be quite unproblematic even if the changes are quite fast. For electrical lighting rapid changes should be avoided. Finally, may strict and repeating geometrical luminance patterns made by shading devices be avoided.

Even more difficult with regard to measures is the psychological or emotional aspects of light. However, some aspects are possible to quantify. Daylight has a positive impact on the experience of space, the effect increases with the size of window. Electrical lighting on the other hand may either have a positive or negative impact on the experience of space depending on other qualitative measures. Both natural and electric light, if delivered in a proper way, have positive impact on learning progress in schools. The window size should not be minimized also because of the view out of the window, which has positive effect on well-being, especially if the quality of the view is high and/or the view contains greenery.

The final aspect is the non-image forming effects of light. There is so much evidence today that we could say that there are non-image forming effects of light with theoretical biologically based valid models. The development of knowledge of molecular endocrinology is rapid as is the neuro-physiological knowledge. New knowledge may change the recommendations. Daylight is suitable since our biological apparatus is developed for this. Electrical lighting should be developed in line with the new knowledge. However, technical problems will occur since it is very difficult to mimic daylight. The temporal aspect with light and darkness should not be underestimated. 
Measures for these aspects have been developed but are not standardized yet. The problem related to the high amount of time spent indoors should not be neglected. It is important to use the daylight as much as possible.

The advantages with daylight are both related to human needs but also to the energy efficiency. In countries where there is good access to daylight the year around, the daylight should be used during day hours. In countries far from the equator where there are big differences over the year, daylight harvesting is of even higher importance. The research suggest that daylight controlled for glare is to prefer in relation to electrical light in nearly all occasions. Electrical lighting should be seen as a complement to daylight.

As Mark Rea so fruitfully described in his book Value metrics for lighting (2013) light is not just light, depending on the situation there are different needs. Added to this is the energy saving perspective, the measures used should be representing value of both quality of light and energy efficiency.

\section{Reference}

Rea, M.S. (2013) Value Metrics for Better Lighting. SPIE Press

Repro-Light (2020) Re-usable and re-configurable parts for sustainable LED-based lighting systems, EU H2020 research project, https://www.repro-light.eu/

Table 1. Application-related requirements for office work, based on the literature review, standards EN-17037 and EN-12464, and the requirements specification according to the EU H2020 research project "Repro-light".

\begin{tabular}{|c|c|c|c|c|}
\hline \multirow[b]{2}{*}{ Parameter } & \multicolumn{2}{|l|}{ Daylight } & \multicolumn{2}{|c|}{ Electric light } \\
\hline & Measure & Standard value & Measure & Standard value \\
\hline \multirow[t]{2}{*}{$\begin{array}{l}\text { Workplace } \\
\text { illuminance } \\
\text { General }\end{array}$} & $\begin{array}{l}\text { Target illuminance of } \\
\text { daylight provision } \\
\text { from windows }\end{array}$ & $\begin{array}{l}\geq 300 \text { lux on the } \\
\text { working place level } \\
\geq 50 \% \text { of the yearly } \\
\text { daylight hours } \\
\geq 50 \% \text { of the space } \\
\text { area }\end{array}$ & \multirow[t]{2}{*}{$\begin{array}{l}\text { Mean } E_{h} \\
\text { on the desk }\end{array}$} & \multirow[t]{2}{*}{$\begin{array}{l}\text { Together with } \\
\text { daylight } \\
\geq 500 \text { lux }\end{array}$} \\
\hline & Spaces with skylights & $\begin{array}{l}\text { as for windows but } \\
\geq 95 \% \text { of the space } \\
\text { area }\end{array}$ & & \\
\hline $\begin{array}{l}\text { Workplace } \\
\text { illuminance } \\
\text { Visual } \\
\text { demanding }\end{array}$ & $\begin{array}{l}\text { daylight provision } \\
\text { from windows }\end{array}$ & $\begin{array}{l}\geq 750 \text { lux on the desk } \\
\geq 50 \% \text { of the yearly } \\
\text { daylight hours }\end{array}$ & $\begin{array}{l}\text { Mean } E_{h} \\
\text { on the desk }\end{array}$ & $1000 \operatorname{lux}$ \\
\hline $\begin{array}{l}\text { Workplace } \\
\text { illuminance } \\
\text { homogeneity }\end{array}$ & $\begin{array}{l}\text { Minimum Target } \\
\text { illuminance of } \\
\text { Daylight provision } \\
\text { from windows }\end{array}$ & $\begin{array}{l}\geq 100 \text { lux on the } \\
\text { working level in room } \\
\geq 50 \% \text { of the yearly } \\
\text { daylight hours } \\
\geq 95 \% \text { of the space } \\
\text { area }\end{array}$ & $\begin{array}{l}\text { Uniformity } \\
U_{\circ}\left(E_{\text {min }}: E_{\text {mean }}\right) \\
\text { on the desk }\end{array}$ & $\geq 0.6$ \\
\hline $\begin{array}{l}\text { Workplace } \\
\text { illuminance } \\
\text { homogeneity } \\
\text { Visual } \\
\text { demanding }\end{array}$ & $\begin{array}{l}\text { Minimum Target } \\
\text { illuminance of } \\
\text { Daylight provision } \\
\text { from windows }\end{array}$ & $\begin{array}{l}\geq 200 \text { lux on the } \\
\text { working level in room } \\
\geq 50 \% \text { of the yearly } \\
\text { daylight hours } \\
\geq 95 \% \text { of the space } \\
\text { area }\end{array}$ & $\begin{array}{l}\text { Uniformity } \\
\mathrm{U}_{\circ}\left(\mathrm{E}_{\text {min }}: \mathrm{E}_{\text {mean }}\right) \\
\text { on the desk }\end{array}$ & $\geq 0.7$ \\
\hline $\begin{array}{l}\text { Movement area } \\
\text { illuminance }\end{array}$ & No measure & $\begin{array}{c}\text { Low daylight } \\
\text { illuminance is } \\
\text { accepted }\end{array}$ & Mean $E_{h}$ & $200 \operatorname{lux}$ \\
\hline $\begin{array}{l}\text { Movement area } \\
\text { illuminance } \\
\text { homogeneity }\end{array}$ & No measure & $\begin{array}{l}\text { Low daylight } \\
\text { illuminance } \\
\text { homogeneity is } \\
\text { accepted }\end{array}$ & $U_{0}\left(E_{\text {min }}: E_{\text {mean }}\right)$ & 0.4 \\
\hline
\end{tabular}




\begin{tabular}{|c|c|c|c|c|}
\hline $\begin{array}{l}\text { Colour of light in } \\
\text { general }\end{array}$ & No measure & $\begin{array}{c}\text { Natural variation of } \\
\text { colour of daylight is } \\
\text { appreciated }\end{array}$ & $\mathrm{CCT}(\mathrm{K})$ & $3000-5000$ \\
\hline $\begin{array}{l}\text { Colour of light } \\
\text { Wards }\end{array}$ & No measure & $\begin{array}{c}\text { blue and green tint of } \\
\text { window glass should } \\
\text { be avoided }\end{array}$ & $\mathrm{CCT}(\mathrm{K})$ & $4000 \leq T_{c p} \leq 5000$ \\
\hline $\begin{array}{l}\text { Workplace } \\
\text { colour rendition }\end{array}$ & $\begin{array}{l}\text { Colour rendering for } \\
\text { window glass }\end{array}$ & $\begin{array}{l}\text { hue shift } \leq 30 \\
\text { saturation shift } \\
\leq 30\end{array}$ & $\begin{array}{l}\mathrm{CRI} \text { (additional } \\
\left.\mathrm{R}_{12}\right)\end{array}$ & $\geq 80$ \\
\hline $\begin{array}{l}\text { Workplace } \\
\text { colour rendition } \\
\text { Colour quality } \\
\text { demanding } \\
\end{array}$ & $\begin{array}{l}\text { Colour rendering for } \\
\text { window glass }\end{array}$ & $\begin{array}{l}\text { hue shift } \leq 10 \\
\text { saturation shift } \\
\leq 20\end{array}$ & $\begin{array}{l}\text { CRI (additional } \\
\left.\mathrm{R}_{12}\right)\end{array}$ & $\geq 90$ \\
\hline \multirow{3}{*}{$\begin{array}{l}\text { View out to the } \\
\text { outside from the } \\
\text { workplace }\end{array}$} & Width of the view & $>14^{\circ}$ & - & - \\
\hline & Length of the view & $>6 \mathrm{~m}$ & - & - \\
\hline & $\begin{array}{l}\text { Number of view } \\
\text { layers (ground, } \\
\text { landscape, sky) }\end{array}$ & $\begin{array}{l}\text { Minimum landscape } \\
\text { layer is visible }\end{array}$ & - & - \\
\hline Glare & $\begin{array}{l}\text { Daylight glare } \\
\text { probability } \\
D G P_{\mathrm{e}<5 \%}\end{array}$ & $\begin{array}{l}<0.45 \\
\text { besides } 5 \% \text { of the } \\
\text { occupation time }\end{array}$ & UGR & $\leq 19$ \\
\hline $\begin{array}{l}\text { Luminance in } \\
\text { the visual field }\end{array}$ & $\begin{array}{l}\text { Max. luminance of the } \\
\text { window surface for } \\
\text { workplaces in } \\
\text { neighbourhood of } \\
\text { window }\end{array}$ & $\leq 4000 \mathrm{~cd} / \mathrm{m}^{2}$ & $\begin{array}{l}\text { Max. luminance at } \\
\text { gamma }>60^{\circ}\end{array}$ & $\leq 3000 \mathrm{~cd} / \mathrm{m}^{2}$ \\
\hline $\begin{array}{l}\text { Repeating } \\
\text { luminance } \\
\text { contrasts }\end{array}$ & $\begin{array}{l}\text { Spatial frequency on } \\
\text { the window surface }\end{array}$ & $\begin{array}{l}\text { Avoid strong } \\
\text { luminance contrast in } \\
\text { the medium } \\
\text { frequencies } \\
(0,2-0,5)\end{array}$ & $\begin{array}{l}\text { Multishadows } \\
\text { from lamps } \\
\text { Mean illuminance } \\
\text { at surface level }\end{array}$ & $\geq 100 \operatorname{lux}$ \\
\hline $\begin{array}{l}\text { Homogeneity of } \\
\text { light-emitting } \\
\text { surface }\end{array}$ & & & $\begin{array}{l}\mathrm{L}=(\mathrm{L}(90 \%): \\
\mathrm{L}(10 \%) / L_{\text {average }}\end{array}$ & \\
\hline $\begin{array}{l}\text { Non-visual } \\
\text { effects of light } \\
\text { (daytime work) }\end{array}$ & & $\begin{array}{l}\text { Daylight is } \\
\text { recommended } \\
\text { wherever possible. }\end{array}$ & $\begin{array}{l}\text { Circadian stimulus } \\
\text { [CS] }\end{array}$ & $\begin{array}{l}\geq 0.3^{*} \text { (Practically } \\
\geq 0.4 \text { ) throughout } \\
\text { the day }\end{array}$ \\
\hline $\begin{array}{l}\text { Non-visual } \\
\text { effects of light } \\
\text { (shift work) }\end{array}$ & & & $\begin{array}{l}\text { circadian stimulus } \\
\text { [CS] }\end{array}$ & $\begin{array}{l}C S \geq 0.3 \text { throughout } \\
\text { first part of the shift } \\
\text { (until about } 05: 00 \\
\text { am), and then } \\
\text { shielding } \\
\text { themselves from } \\
\text { exposure to } \\
\text { circadian-effective } \\
\text { light until they are } \\
\text { home and in their } \\
\text { darkened bedroom } \\
\text { for sleep }\end{array}$ \\
\hline
\end{tabular}

The green background to mark requirements for visual demanding tasks

The blue background to mark requirements with special importance of colour rendering. 